Article

\title{
Experimental and Numerical Investigations on Heat Transfer of Bare Tubes in a Bubbling Fluidized Bed with Respect to Better Heat Integration in Temperature Swing Adsorption Systems
}

\author{
Hannes Vogtenhuber ${ }^{1}$, Dominik Pernsteiner ${ }^{1}$ and René Hofmann ${ }^{1,2, *}$ \\ 1 Technische Universität Wien, Institute for Energy Systems and Thermodynamics, Getreidemarkt 9/BA, \\ 1060 Wien, Austria \\ 2 AIT Austrian Institute of Technology GmbH, Center for Energy, Sustainable Thermal Energy Systems, \\ Giefinggasse 2, 1210 Wien, Austria \\ * Correspondence: rene.hofmann@tuwien.ac.at
}

Received: 14 June 2019; Accepted: 8 July 2019; Published: 10 July 2019

\begin{abstract}
In this paper experimental and numerical investigations on heat transfer within a bubbling fluidized bed will be presented with respect to better heat integration in continuous temperature swing adsorption (TSA) processes for biogas upgrading. In the literature, mainly heat transfer measurements with glass or sand particles are carried out, thus special reference measurements with adsorbent material in a fluidized bed are missing. Therefore firstly, a series of experiments were carried out in the fluidized bed test facility to obtain heat transfer coefficients between tube surface and bed which were then compared to calculated heat transfer coefficients to determine whether suitable models were available. Horizontal bare tubes with different arrangements (i.e., single tubes and especially tube bundles) are immersed in fluidized amine layered particles with a mean diameter of $650 \mu \mathrm{m}$ which are used in the adsorption industry as adsorbent. The test facility enables a cross-current flow of the solids and gas phase as it prevails in a multi-stage fluidized bed reactor for TSA-applications. The heat transfer measurements with different arrangements and adsorbent material show very similar values in the range of $200 \mathrm{~W} / \mathrm{m}^{2} \mathrm{~K}$. The mathematical model for single tubes multiplied by a tube diameter factor shows approximate agreement with the experimental results. However, the mathematical models for tube bundles were not able to predict the measured heat transfer coefficients with the required accuracy. Secondly, a computer fluid dynamics (CFD) program was used to perform a numerical investigation of the test facility using the Euler-Euler method in order to describe the required two-phase characteristic of a fluidized bed. The results of the numerical simulation were compared and validated with the experimental results. Bubbling fluidized bed flow regimes could be reproduced well but the heat transfer coefficients between tube and bed were clearly underestimated. However, a numerical study for a bubbling fluidized bed with external circulation, as used in novel continuous TSA systems, could be carried out and thus a tool for better heat integration measures was developed.
\end{abstract}

Keywords: temperature swing adsorption; bubbling fluidized bed; heat transfer; modeling; simulation

\section{Introduction}

Nowadays, it becomes more important to ensure low carbon emissions from industry and power plants. This may be done with the help of bio-methane from biogas upgrading. To fulfill the quality requirements for supplying bio-methane to the natural gas grid, separation from $\mathrm{CO}_{2}$ is required. 
This task can be done via continuous temperature swing adsorption (TSA) within a bubbling fluidized bed system.

Temperature swing adsorption based on a moving bed is often used in the field of flue gas cleaning by $\mathrm{CO}_{2}$-capture and shows an acceptable effectiveness [1]. The recently proposed TSA-system [2] by the authors of this work for biogas upgrading uses fluidized bed technology in order to achieve higher heat transfer rates compared to fixed or moving beds [3,4]. The separation process is operating at medium temperatures and atmospheric conditions [2]. For excellent process control, it is essential to maintain a certain temperature within the fluidized bed due to the adsorption isotherms and therefore adsorption/desorption activity of the $\mathrm{CO}_{2}$ on the amine adsorbents. During the exothermic adsorption step active cooling is required and vice-versa active heating during the endothermic desorption step. Hence, in-bed heat exchangers are applied to the fluidized bed TSA-process to avoid deviation from efficient adsorption/desorption temperatures. The resulting heat transfer coefficient (HTC) between the fluidized bed and immersed heat exchangers influences the thermodynamic driving force for separation and moreover, the overall performance and economics of a TSA-process [2]. However, heat transfer between a fluidized bed and an immersed object depends on a number of process-factors [5-12], including particle (i.e., type of Geldart) and gas properties, in-bed object geometry (i.e., heat exchanger layout) and of course fluidization rate. The TSA-process considers particles of Geldart type B [13] in terms of solids well-mixed behaviors [13] for acceptable $\mathrm{CO}_{2}$ capture performance [14].

In general, the heat transfer coefficient $h_{F B}$ between an immersed tube-wall and a fluidized bed is shown in Equation (1) and can be split into three terms of particle convection $h_{p c}$, gas convection $h_{g c}$ and radiation $h_{\text {rad }}$.

$$
h_{F B}=h_{p c}+h_{g c}+h_{r a d}
$$

The particle convection describes the conducted heat transfer from the particle to the surface between a thin remaining gas layer. In most gas-solids fluidized beds, the particle convection is predominat [15]. The gas convection describes the heat transport between gas and surface. It becomes important for denser and larger particles [15]. The radiative term of the heat transfer coefficient becomes significant only for bed temperatures above $400{ }^{\circ} \mathrm{C}(870 \mathrm{~K})$ [16] and can be neglected for TSA-applications (i.e., max. process-temperature $\left.120^{\circ} \mathrm{C}(390 \mathrm{~K})\right)$.

Literature offers many experimental and numerical investigations on the heat transfer coefficients from wall-to-bed in fluidized beds as well as mathematical correlations for HTC. For example, some heat transfer models are based on a cluster renewal approach model [5,17-19], on a fuzzy logic model [17], or a semi-empirical packet-renewal model [6] to predict mechanistic HTC. Zarghami et al. [20] developed a model for departure rate of particle from the surface element to the fluidized bed. The models by Molerus et al. [21,22], Natusch et al. [23] and Martin [24] are able to describe the fluidized bed HTC as a function of the fluidization gas velocity. This property of the mathematical models is particularly important for the design of optimized in-bed heat exchangers of TSA-systems. The last named models have been developed for single tubes immersed in fluidized bed.

To consider tube bundle configurations for heat exchanger design, some models are designed to calculate tube bundle reduction factors [11,25], which can be multiplied to the single tube models. According to Hofer et al. [26], the particle diameter, tube diameter and tube bundle spacing have a significant influence on the heat transfer rates and furthermore, the models by Natusch et al. [23] and Molerus et al. [21,22] lead to qualitative and quantitative differences compared to the obtained results.

Therefore, this work will first experimentally investigate the HTC for Geldart type B amine layered bulk material, specially developed for $\mathrm{CO}_{2}$ capture applications. A test facility was set up and heat exchange measurements were carried out on single tubes and in particular tube bundles in different configurations within a fluidized bed similar to a TSA-reactor. The aim is to provide information about which HTC values can be expected from the experimental investigations of the adsorbent material and thus, which mathematical models can predict them best. Suitable mathematical models can be used for dimensioning in-bed heat exchangers for TSA reactors and full heat integration can be achieved. 
The second part of the work will be a numerical analysis with the computer fluid dynamics (CFD) program ANSYS ${ }^{\circledR}$ Fluent ${ }^{\circledR}$ using Euler-Euler method of the proposed test facility in order to investigate flow characteristics and heat transfer of it. Furthermore, only a few numerical studies on both regime and heat transfer have been performed on bubbling fluidized beds with external circulation. This numerical study aims to show how the flow characteristics and heat transfer coefficient is influenced by the geometric shape of the immersed in-line heat exchanger surface. For this, the Euler-Euler method was combined with the kinetic theory of granular flows. The kinetic theory of granular flows was used in various heat transfer studies in a fluidized bed to predict the heat transfer coefficients of a fluidized bed with an immersed object [27]. The influence of different thermal conductivities, drag models and specularity coefficients on the fluidization regime and heat transfer is also shown. The previously obtained experimental data from the test facility can be used for validation. Furthermore, the proposed modeling of a fluidized bed with external material inlet and outlet is supposed to create a simulation that allows faster and more flexible investigations of different heat exchanger geometries for multi-stage fluidized bed TSA-systems. This means, that the time-consuming design and construction of cold flow models with different heat exchanger geometries for performance studies can be avoided.

\section{Experimental Investigation}

For experimental investigations on heat transfer between bubbling fluidized bed and immersed bare tubes, a novel test facility at atmospheric test conditions with temperature swing adsorption process characteristics (i.e., external material circulation and amine layered bulk material) has been constructed and deployed.

\subsection{Materials and Experimental Test Facility}

\subsubsection{Test Facility}

Figure 1 shows the main parts of the test facility. In the bottom, air was introduced into the windbox and the gas distribution plate enables a homogenous distribution of air for fluidization. To enable an external bulk material circulation, two sideward placed tubes facilitated material transport. Thus, the fluidized bed test facility transports the solids material through the bed in a cross-current flow with the immersed heat exchanger layout. The aim was to indicate a counter-cross heat exchanger, but nevertheless real fluidized bed regime behaviors within the test facility were similar to a cross-current application. Above the fluidized bed, the arising freeboard with the air outlet is located on the top of the facility.

The dimension of the bed height was up to $320 \mathrm{~mm}$ at superficial gas velocity of $0.13 \mathrm{~m} / \mathrm{s}$ in a square cross section with a lateral length of $200 \mathrm{~mm}$. Figure 2 shows the test facility with and without bulk material and on the right the aluminum dummies in a staggered layout. To control the external circulating rate of the test facility, air was used to adapt the solids material throughput in the L-valve and therefore the transport within the riser into the air/solids material separator. The throughput of the solids material quantity was set via a pre-experimental evaluation. This was determined by the volume flow of the air and the cross-section of the L-valve. After separation the solids material flows back into the fluidized bed. Dry compressed air was used as the fluidization agent and can be provided with a volume flow in the range of $2.5-100 \mathrm{Nm}^{3} / \mathrm{h}$. Due to absolutely dry air behaviors, it had to be moisturized through a moistening system to avoid possible electrostatic potential of the bulk material. Hence, the relative humidity of the compressed air can be adjusted in the range between $0 \%$ and $40 \%$. 


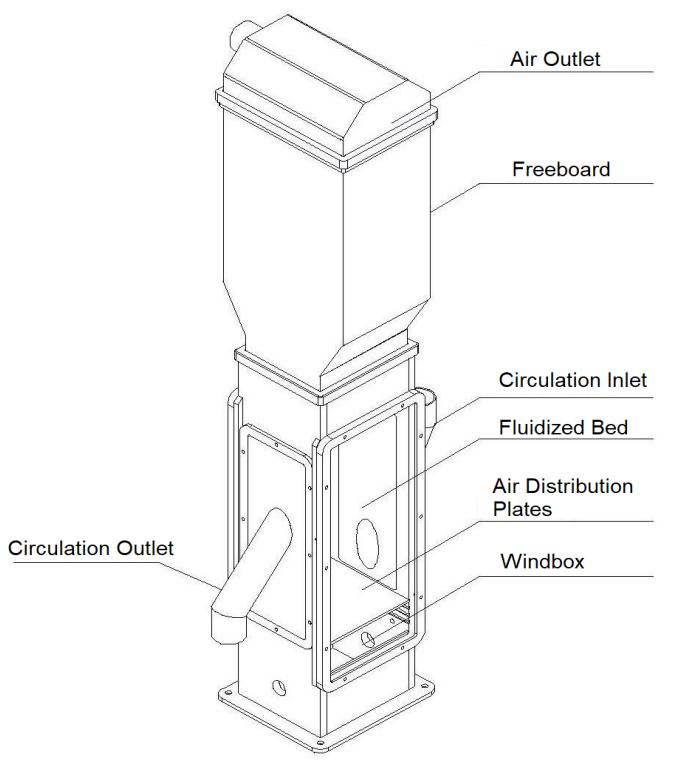

Figure 1. Schematic design sketch of the experimental test facility.
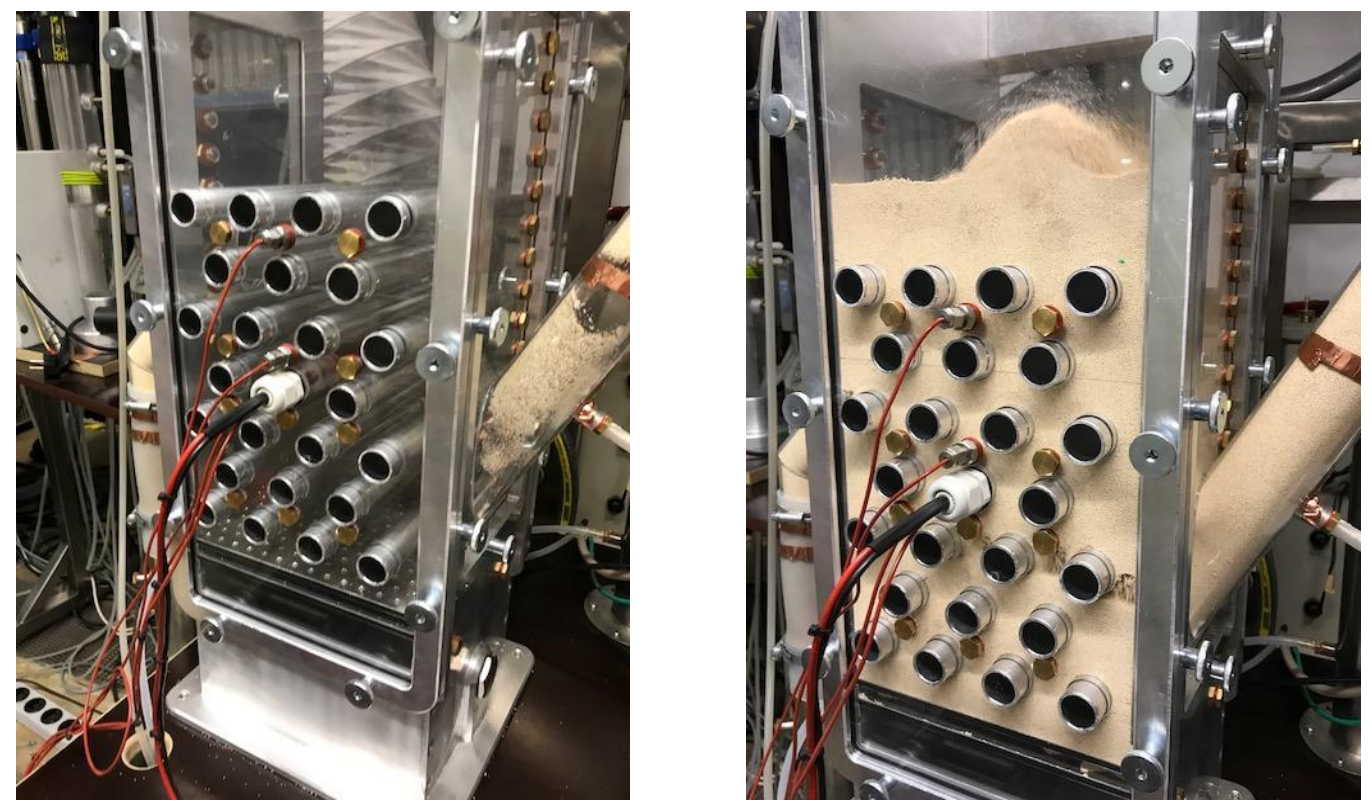

Figure 2. Illustrations of the computer fluid dynamics (CFB) test facility for heat transfer measurements: (left) shows the facility without bed material, and (right) shows filled bed material. Both have staggered heat exchanger layouts.

The heating probe (Figure 3) was divided into three sections: in the center an electrically heated copper part is placed, surrounded by two acrylic glass ends to ensure that the entire heat is transferred to the fluidized bed.

Thermocouple

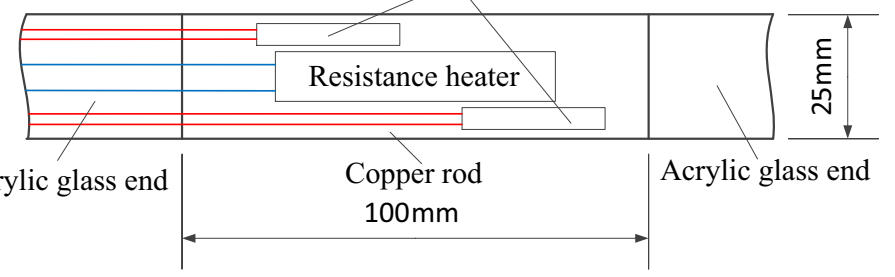

Figure 3. Schematic sketch of the heating probe. 
The electrical power consumption of the heating probe $P_{e l}=\dot{Q}$ was measured and two thermocouples (1/3DIN standard) determined the temperature of the heating probe $\left(T_{H P 1}\right.$ and $\left.T_{H P 2}\right)$. The surface temperature of the copper part was set to $65^{\circ} \mathrm{C}(338 \mathrm{~K})$, by measuring and controlling the voltage $U$ and current $I$ of the power supplier. Two separate thermocouples (1/3DIN standard) were placed on the acrylic glass plates at different positions (Figure 4) to measure the bed temperature $\left(T_{F B 1}\right.$ and $\left.T_{F B 2}\right)$. Furthermore, as a result of the mixing due to the bubble movement, a fluidized bed had a high effective thermal conductivity in the vertical direction. As a consequence, temperature gradients were immediately reduced and almost isothermal conditions occur [28]. Thus, the position of the thermocouples was chosen that the position $T_{F B 1}$ was immediately after the heating probe and the position $T_{F B 2}$ in the bed inner (staggered and single) or on the opposite of the heating probe and $T_{F B 1}$, respectively, (in-line) for a good prediction of the HTC between heating probe and fluidized bed. The electric power consumption and all temperatures were recorded during the measurements. The following Table 1 gives an overview of the different experimental test facility parameters.
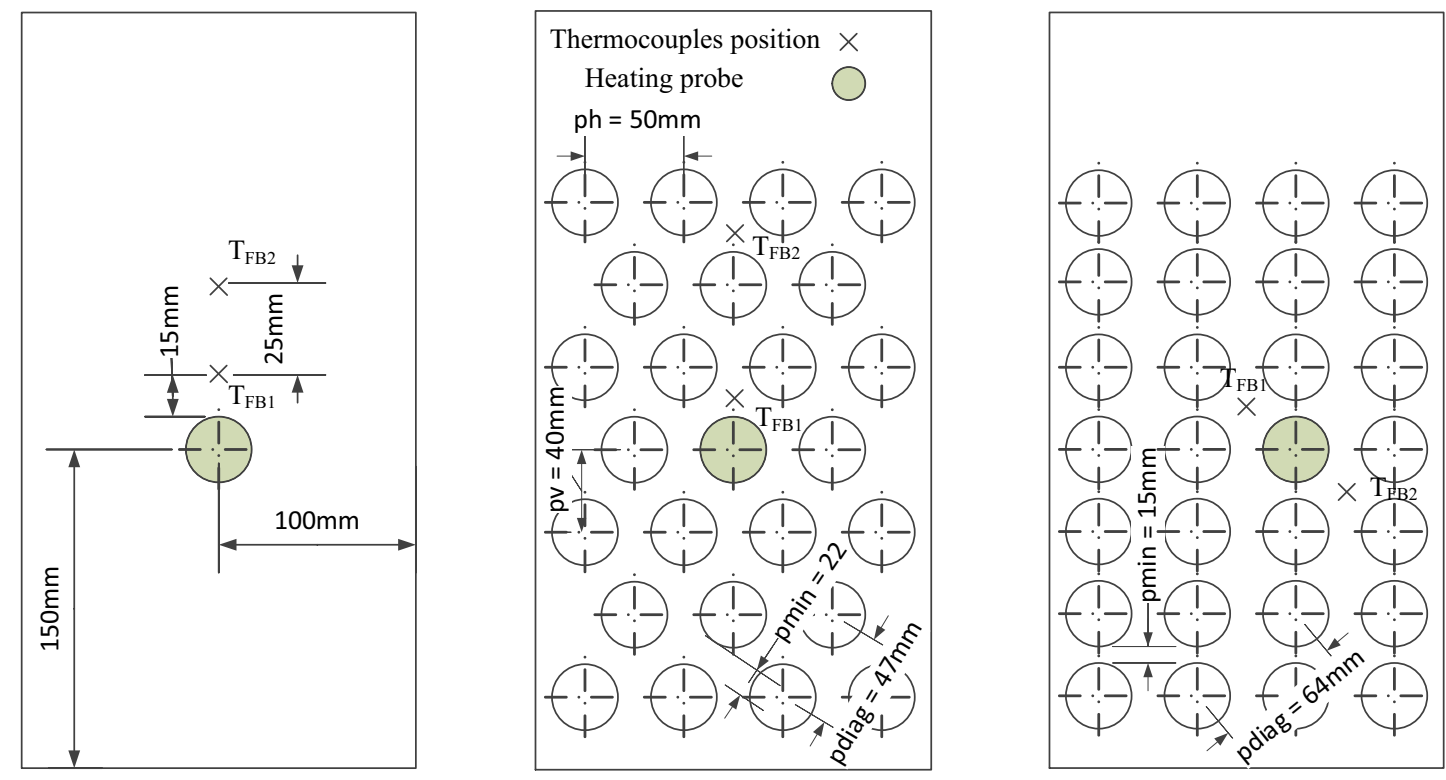

Figure 4. Used front plates with different layouts (single, staggered, inline) of the bare tubes.

Table 1. Test facility and experimental parameters.

\begin{tabular}{cccccccccccc}
\hline & $\begin{array}{c}d_{s} \\
{[\mu \mathbf{m}]}\end{array}$ & $\begin{array}{c}u_{m f} \\
{[\mathbf{m} / \mathbf{s}]}\end{array}$ & $\begin{array}{c}u \\
{[\mathbf{m} / \mathbf{s}]}\end{array}$ & $\begin{array}{c}S C R \\
{[\mathbf{k g} / \mathbf{h}]}\end{array}$ & $\begin{array}{c}d_{t} \\
{[\mathbf{m m}]}\end{array}$ & $\begin{array}{c}p_{v} \\
{[\mathbf{m m}]}\end{array}$ & $\begin{array}{c}p_{h} \\
{[\mathbf{m m}]}\end{array}$ & $\begin{array}{c}p_{\text {min }} \\
{[\mathbf{m m}]}\end{array}$ & $\begin{array}{c}p_{\text {diag }} \\
{[\mathbf{m m}]}\end{array}$ & $\begin{array}{c}s_{h} \\
{[-]}\end{array}$ & $\begin{array}{c}s_{\text {diag }} \\
{[-]}\end{array}$ \\
\hline ST & 650 & 0.105 & $0.13-0.5$ & 100 & 25 & - & - & - & - & - & - \\
TB inline & 650 & 0.105 & $0.13-0.5$ & 100 & 25 & 40 & 50 & 15 & 64 & 2 & 2.56 \\
TB stag. & 650 & 0.105 & $0.13-0.5$ & 100 & 25 & 40 & 50 & 22 & 47 & 2 & 1.88 \\
\hline
\end{tabular}

The experimental solids circulation rate (SCR) was set to $100 \mathrm{~kg} / \mathrm{h}$ during all operations. The test facility contained removable acrylic glass plates for different tube layouts. The acrylic glass plates had seven rows in transverse and four or three holes in longitudinal direction, depending on the arrangement (Figure 4). To imitate immersed heat exchangers, these plates held aluminum dummies with a diameter of $d_{t} 25 \mathrm{~mm}$ and the heating probe in the same dimension, already shown in Figure 2 (middle and right). Figure 4 shows even the different geometry properties where $s_{h}=\frac{p_{h}}{d_{t}}$ is the horizontal spacing and $s_{\text {diag }}=\frac{p_{\text {diag }}}{d_{t}}$ the diagonal spacing (Table 1 ). The permeability $\frac{d_{p}}{p_{t}}$ is the rate of mean particle diameter and minimum free distance between tube walls. 


\subsubsection{Bulk Material}

The measurements were conducted at ambient conditions with Lewatit ${ }^{\circledR}$ VP OC 1065 as bulk material. Lewatit ${ }^{\circledR}$ VP OC 1065 consists of a polystyrene polymer and functionalized with primary amine groups [29]. Table 2 illustrates the important material data. This adsorption material was rated as thermally and mechanically stable and shows excellent $\mathrm{CO}_{2}$ capture properties in a continuous TSA process [29].

Table 2. Material properties (Lewatit ${ }^{\circledR}$ VP OC 1065).

\begin{tabular}{cc}
\hline Description & Value \\
\hline Particle diameter $d_{\mathrm{s}}$ & $0.650[\mathrm{~mm}]$ \\
Bulk density $\rho_{\text {bulk }}$ & $525\left[\frac{\mathrm{kg}}{\mathrm{m}^{3}}\right]$ \\
Particle density $\rho_{\mathrm{s}}$ & $812.2\left[\frac{\mathrm{kg}}{\mathrm{m}^{3}}\right]$ \\
Material particle density (polystyrene) $\rho_{\text {material }}$ & $1040\left[\frac{\mathrm{kg}}{\mathrm{m}^{3}}\right]$ \\
Max. bulk limit $\alpha_{\max }$ & $0.65[-]$ \\
Inner angle of friction $\phi_{\mathrm{c}}$ & $22.8\left[{ }^{\circ}\right]$ \\
Collision factor $e_{\mathrm{s}}$ & $0.92[-]$ \\
Specific pore volume $v_{\text {pore }}$ & $0.27\left[\frac{\mathrm{cm}^{3}}{\mathrm{~g}}\right]$ \\
Thermal conductivity $\kappa_{\mathrm{s}}($ replacement) & $0.16\left[\frac{\mathrm{W}}{\mathrm{m}}\right]$ \\
Density ambient air $\rho_{1}=$ pore density $\rho_{\text {pore }}$ & $1.2041\left[\frac{\mathrm{kg}}{\mathrm{m}^{3}}\right]$ \\
Specific heat capacity $c_{\mathrm{p}, \mathrm{s}}$ & $1500\left[\frac{\mathrm{mg} \mathrm{K}}{\mathrm{kg}}\right]$ \\
\hline
\end{tabular}

The particle diameter of Lewatit ${ }^{\circledR}$ VP OC 1065 is clearly in the Geldart type B range [13], as indicated in Figure 5.

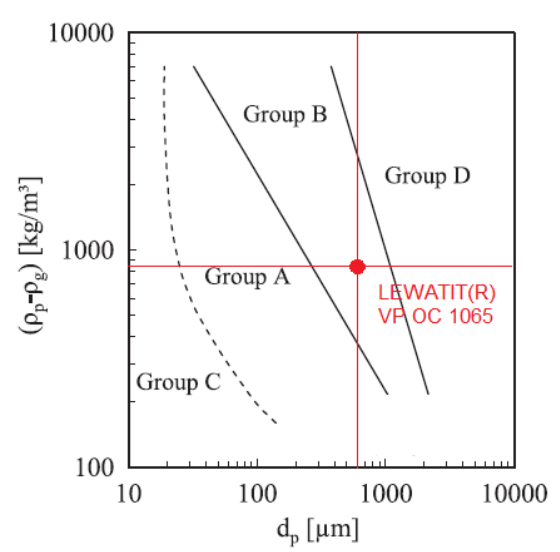

Figure 5. Geldart type [13] classification of Lewatit ${ }^{\circledR}$ VP OC 1065 (adapted from [26]).

The minimal fluidization velocity $u_{\mathrm{mf}}$ can be estimated at $0.105 \mathrm{~m} / \mathrm{s}$ for the inserted Lewatit ${ }^{\circledR} \mathrm{VP}$ OC 1065, according to Equation (2) [30].

$$
u_{m f}=\frac{\mu_{g}}{\rho_{g} d_{s}}\left(\sqrt{33.7^{2}+0.0408 \cdot A r}-33.7\right) .
$$

The Archimedes number $A r$ is the ratio of the buoyancy force of the particles to the viscous forces of the fluidization gas.

$$
A r=\frac{d_{s}^{3}\left(\rho_{p}-\rho_{g}\right) \rho_{g} g}{\mu_{g}^{2}} .
$$

The collision factor for solid-solid impact was the ratio between the relative velocities and is usually determined experimentally. Since the bulk material was also a polystyrene variant, a collision factor of 0.92 is selected [31]. 


\subsection{Measurement Procedure}

The measurements of the power consumption of the heating probe and the temperatures of heat probe and fluidized bed are needed to calculate the HTC at adjusted conditions. The measured bed temperature $T_{F B}$ was calculated as arithmetic mean between $T_{F B 1}$ and $T_{F B 2}$ as well as the heating probe temperature $T_{H P}$ as arithmetic mean between $T_{H P 1}$ and $T_{H P 2}$. In order to calculate the HTC from the measured data, the measured temperature of the heating probe was defined as the surface temperature of the heating probe. With this assumption the apparent heat transfer coefficient $h_{F B}$ can be calculated as follows

$$
h_{F B}=\frac{P_{e l}}{A_{H P}\left(T_{H P}-T_{F B}\right)} .
$$

The bed temperature and the power were measured after reaching the thermodynamic equilibrium at approx. $10 \mathrm{~min}$ and further, the sampling frequency of the temperature signal was set to $5 \mathrm{~s}$ during measurement.

\subsection{Measurement Uncertainty}

An analysis of measurements required an examination on uncertainties of the measured results. The calculation of uncertainty was conducted according to DIN 1319 [32] and enabled a qualitative analysis of the measurement results. The mathematical method subdivided the measured values into the true value, the random error and the systematic error. The assumption was made that rough errors were prevented. These errors were not avoidable but random errors can reduced by increasing the number of recorded measurands of the same measured values under repeatability conditions. Systematic errors are dividable into known and unknown systematic errors. The propagation of the uncertainty is given through the well known measured uncertainties for the applied system. According to Equation (5), $F$ is the determined function of the $n$ measured values $f_{i}$. The uncertainty, which is defined as the absolute error, has the same unit as the measured value.

$$
\delta F= \pm\left\{\sum_{i=1}^{n}\left(\frac{\delta F}{\delta f_{i}}\right)^{2} \delta f_{i}^{2}\right\}^{\frac{1}{2}} .
$$

The apparent heat transfer coefficient is determined with Equation (6) and the assumption of $\dot{Q}=P_{e l}=U I$.

$$
h=\frac{\dot{Q}}{A_{H P} \Delta T}=\frac{U I}{A_{H P} \Delta T} .
$$

The heat transfer coefficient is a function of heating probe surface $A_{H P}$, temperature difference $\Delta T$ between bubbling fluidized bed (FB) and heating probe (HP) and electrical power supply $P_{e l}$. The uncertainty of the heat transfer coefficient is given by evaluating the partial derivations with respect to $T_{F B}, T_{H P}$ or $P_{e l}$ in terms of applying the law of uncertainty propagation and follows Equation (7).

$$
\delta h= \pm\left\{\left(\frac{\delta h}{\delta P_{e l}}\right)^{2} \delta P_{e l}^{2}+\left(\frac{\delta h}{\delta T_{F B}}\right)^{2} \delta T_{F B}^{2}+\left(\frac{\delta h}{\delta T_{H P}}\right)^{2} \delta T_{H P}^{2}\right\}^{\frac{1}{2}} .
$$

Equation (7) shows that the temperature difference between heating probe and fluidized bed has an important influence on the measurement uncertainty for the heat transfer coefficient.

The structured relative uncertainties of the heat transfer coefficient over the the number of measurements $N_{i}$ are illustrated in Figure 6 . The results of the calculated measurement uncertainty indicated that approximately $80 \%$ of the measured values had a relative uncertainty beneath $4 \%$. 


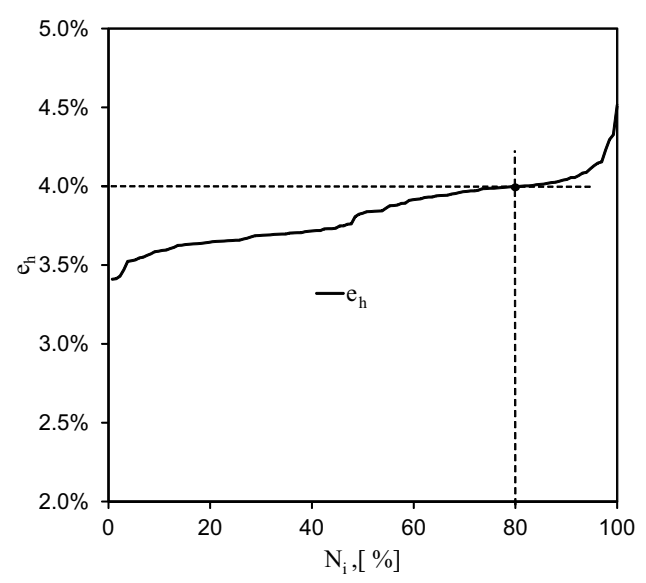

Figure 6. Relative uncertainties of the heat transfer coefficient.

\subsection{Mathematical Models}

Mathematical models from the literature were used to calculate heat transfer coefficients in fluidized beds to compare them with the experimentally determined HTCs. The models and factors are summarized in Table 3.

The correlation published by Molerus et al. [21,22] and Natusch et al. [23] are able to describe heat transfer coefficients of single tubes within a fluidized bed but were developed under different particle and gas properties than those used in this study. Molerus et al. [21,22] conducted experiments with vertical single tubes and established a detailed calculation for particle and gas convective heat transfer. The model by Molerus et al. [21,22] is valid in the range of Geldart types A-D. The model presented by Natusch et al. [23] is only valid for Geldart type B particles and with a mean diameter of $650 \mu \mathrm{m}$. The relevant coefficients $\mathrm{C} 1$ to $\mathrm{C} 5$ for Natusch et al. [23] are displayed in Table 3 for the used particle diameter.

Table 3. Mathematical models for $h_{F B}$.

\section{Mathematical models for heat transfer coefficient $h_{F B}$}

Model

Natusch et al. [23] (Geldart type B)

$$
h_{\text {Natusch }}=C_{1} \cdot A r^{C_{2}}\left(\frac{u}{u_{m f}}-1\right)^{C_{3}} \cdot\left\{C_{4}+e^{-C_{5}\left(\frac{u}{u_{m f}}-1\right)}\right\}
$$

$C_{1}=0.8236 ; C_{2}=0.2768 ; C_{3}=0.5669 ; C_{4}=0.2693 ; C_{5}=1.175$

Molerus et al. [21,22] (Geldart types A-D)

$$
\begin{aligned}
& \begin{array}{l}
h_{\text {Molerus }}= \\
\left.\frac{0.125 \cdot\left(1-\epsilon_{m f}\right) \cdot\left(1+33.3 \cdot\left(\sqrt[3]{\frac{u-u_{m f}}{u_{m f}}} \cdot \sqrt[3]{\frac{\rho_{p} \cdot c_{p, s}}{\kappa_{g} \cdot g}} \cdot\left(u-u_{m f}\right)\right)^{-1}\right)^{-1}}{1+\left(\frac{\kappa_{g}}{2 \cdot c_{p, p} \cdot \mu_{g}}\right)+\left(1+0.28 \cdot\left(1-\epsilon_{m f}\right)^{2} \cdot \sqrt{\frac{\rho_{g}}{\rho_{p}-\rho_{g}}} \cdot\left(\sqrt[3]{\frac{\rho_{p} \cdot c_{p, s}}{\kappa_{g} \cdot g}} \cdot\left(u-u_{m f}\right)\right)^{2} \cdot \frac{u_{m f}}{u-u_{m f}}\right.}\right)
\end{array} \\
& \left.+0.165 \cdot \operatorname{Pr}^{\frac{1}{3}} \cdot\left(\frac{\rho_{g}}{\rho_{s}-\rho_{g}}\right)^{\frac{1}{3}} \cdot \frac{1}{1+0.05 \cdot \frac{u_{m} f}{u-u_{m f}}}\right\} \cdot \kappa_{g} \cdot\left(\frac{\mu_{g}}{\sqrt{g} \cdot\left(\rho_{s}-\rho_{g}\right.}\right)^{-\frac{2}{3}}
\end{aligned}
$$

Tube diameter factor

Petrie et al. [11]

$$
f_{d t, \text { Petrie }}=\left(\frac{d_{t}}{33.7 \cdot 10^{-3} m}\right)^{-\frac{1}{3}}
$$

Tube bundle factor

Lechner et al. [25] (Geldart type B)

$$
f_{T B, \text { Lechner }}=\left(\frac{d_{t}}{80 \cdot 10^{-3} m}\right)^{-0.3} \cdot\left(1-\frac{1}{s_{h}}\right)^{0.36} \cdot\left(1-\frac{1}{s_{\text {diag }}}\right)^{0.24} \cdot\left(1-\frac{d_{p}}{p_{\text {min }}}\right)^{4} \cdot\left(\frac{d_{t}}{22 \cdot 10^{-3} m}\right)^{0.09}
$$


Furthermore, a heat exchanger tube diameter factor model proposed by Petrie et al. [11] can be multiplied to the model by Molerus et al. [21,22] to consider the impact of tube diameters. Lechner et al. [25] developed a tube bundle reduction factor for comparison theoretical and experimental heat transfer coefficients. Furthermore, a factor model which considers Geldart type B is introduced by Lechner et al. [25], that can be applied to the model by Molerus et al. [21,22] and Natusch et al. [23].

\subsection{Experimental Results and Discussion}

The HTCs of single tube and tube bundle experiments by varying fluidization gas velocity in the range of $0.1 \mathrm{~m} / \mathrm{s}$ to $0.5 \mathrm{~m} / \mathrm{s}$ for $650 \mu \mathrm{m}$ amine particles were carried out. Figure 7 shows the heat transfer coefficients measurements for a single tube and both tube bundles with in-line and staggered arrangement. With regard to the same tube diameter of the single tube and the tube bundles it can be observed that the HTCs were nearly the same. Further, a deviation of the measurement results can be observed by higher fluidization rates. That contradicts the assumption that HTCs from single tube immersed in fluidized beds are usually higher than for corresponding tube bundles due to higher bubble size and bubble velocity and thus, higher particle exchange rates [33]. However, it must be mentioned that with increasing fluidization gas velocity (i.e., $0.4 \mathrm{~m} / \mathrm{s}$ ) the single tube had a significantly increased HTC. Furthermore, it has been noted in literature that staggered arrangement had marginally higher HTCs than in-line arrangement [25]. This phenomena was only obtained after a fluidization velocity of $0.35 \mathrm{~m} / \mathrm{s}$, whereby with increasing fluidization velocity the staggered layout exhibits a higher HTC. The highest rates were achieved at $0.45 \mathrm{~m} / \mathrm{s}$ fluidization gas velocity for the single tube and $0.3 \mathrm{~m} / \mathrm{s}$ fluidization gas velocity for tube bundles. For fluidization gas velocity of $0.3 \mathrm{~m} / \mathrm{s}$ a homogeneous bed temperature of $\sim 303 \mathrm{~K}$ was measured after $10 \mathrm{~min}$.

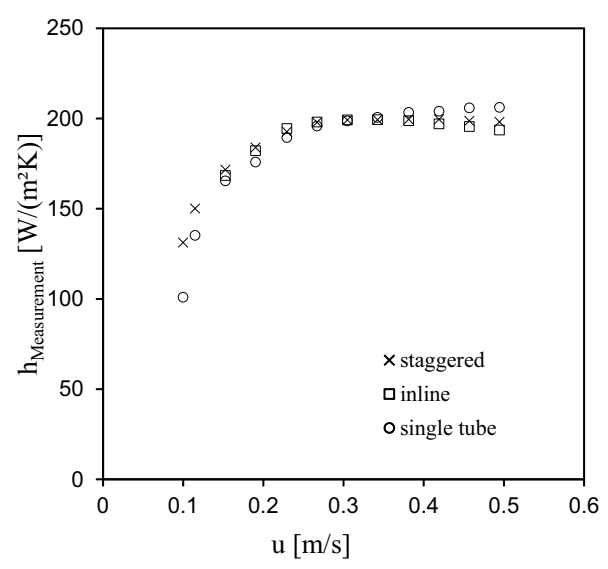

Figure 7. Measured heat transfer coefficients for a single tube and tube bundles with inline and staggered arrangement with $25 \mathrm{~mm}$ outer diameter for $650 \mu \mathrm{m}$ bulk material.

Due to rising high pressure in the windbox of the test facility by increasing the superficial gas velocity, the experimental series stopped at velocities of $0.5 \mathrm{~m} / \mathrm{s}$. It should be pointed out that the maximal heat transfer coefficient was obtained within this velocity range.

First of all, in contrast to the observed HTC from the experiments, the calculated tube bundle models show significantly smaller HTC than single tubes (Figure 8). The calculated heat transfer coefficient by Molerus et al. [21,22] for a single tube was compared to the experimental results for the single tube and is shown in Figure 8. The calculated heat transfer coefficient by Natusch et al. [23] for a single tube deviates more than $30 \%$ (Table 8 ) from the experimental results and thus, was not further represented in Figure 8. The model by Molerus et al. [21,22] was applied with the tube diameter factor model by Petrie et al. [11] and compared with the measurement results. 


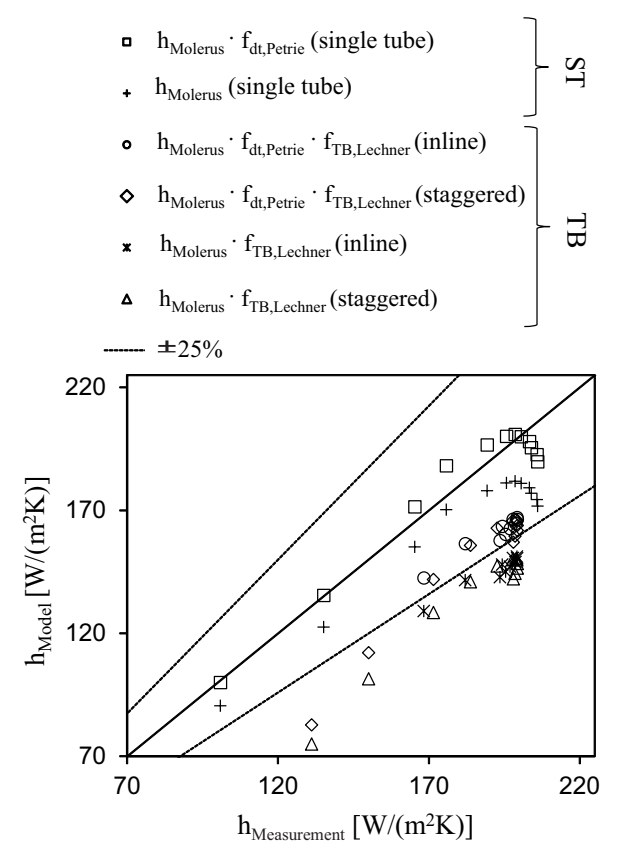

Figure 8. Experimental heat transfer coefficients compared to the mathematical correlations.

The tube bundle measurement results were compared with the introduced models applied with the different factors for inline and staggered layouts, respectively. The initial point was the model by Molerus et al. [21,22] multiplied with the tube bundle factor by Lechner et al. [25] and in separate cases multiplied additionally with the tube diameter factor by Petrie et al. [11]. All used mathematical models were compared, as mentioned before, with the measurement results in Figure 8. The deviation of the heat transfer coefficients between measurement and models are shown in a $\pm 25 \%$ corridor.

The simple model by Molerus et al. [21,22] for gas velocities over $0.2 \mathrm{~m} / \mathrm{s}$ deviated with rising gas velocity more from the obtained heat transfer coefficients. The model by Molerus et al. [21,22] with the additional tube diameter factor by Petrie et al. [11] would be the closest approximation to experimental results for single tubes but after exceeding $0.35 \mathrm{~m} / \mathrm{s}$ the modeled values decreased and the measured values remained approximately constant. The nearest approximation for tube bundle arrangement in-line was given through the model by Molerus et al. [21,22] applied with the factor by Lechner et al. [25] and the tube diameter factor by Petrie et al. [11].

In general, the mathematical models were underestimated for this bulk material and tube bundle geometry. In the following, possible causes for these quantitative discrepancies are listed.

- Due to the very high porosity of the amine layered particles used for $\mathrm{CO}_{2}$ adsorption compared to denser glass beads which are often used for such heat transfer measurements in the literature. Many experiments have different particle size distributions of the bulk material and therefore another mean particle [26]. Molerus et al. [21,22] conducted heat transfer experiments with glass beads at a particle size between $110-670 \mu \mathrm{m}$.

- Hofer et al. [26] points out that experiments for the established models were conducted with various test facilities like different designs of gas distributors and different cross-sectional fluidized bed shapes. Likewise, the various measuring instruments can play an important role in the determination of the HTC.

- Although the gas flow was continuously humidified and kept at approximately $40 \%$ relative humidity, a slight static charge of the particles could be observed during the experiment, which can lead to agglomeration of the particles. 


\section{Numerical Investigation}

To accomplish a satisfying numerical investigation of the introduced test facility above, a suitable CFD method was identified and the descriptive equations for the expected behavior of the fluidized bed were selected. The numerical model of the test facility within this study use the same fluidization rate and in-line heat exchanger layout as used in the experimental part. The numerical fluidization regime and heat transfer values can be validated with the experimental test facility behaviors. Due to model views in the simulation software, the solids inlet and outlet are reversed sideways in the illustrations compared to the real test facility.

\subsection{Mathematical Modeling}

In this work, the Euler-Euler method was used in ANSYS ${ }^{\circledR}$ Fluent ${ }^{\circledR}$ for describing the physical interrelations of the solids and gas phases in a bubbling fluidized bed. The advantage of this method is the briefer calculation time due to the related continuum of all phases. Both phases can be solved independently of each other due to the conservation equations, which are incorporated in ANSYS ${ }^{\circledR}$ Fluent ${ }^{\circledR}$. The properties and calculated flow quantities were considered as averaged values and therefore the control volumes have to be calculated in such a way that this averaging was acceptable. The volume fraction of a phase $q, \alpha_{q}$ was calculated for each control volume and using the Equation (12) the volume of the phase $q$ was obtained. The sum of all volume fractions in a control volume must give one (Equation (13)).

$$
\begin{gathered}
V_{q}=\int_{V} \alpha_{q} d V \\
\sum_{q=1}^{n} \alpha_{q}=1 .
\end{gathered}
$$

The conservation of momentum for different phases is linked through the drag force term and effects the flow conditions, bubble formation and bubble size within a fluidized bed [27]. Most drag force models were developed using empirical data and for a fluidized bed simulation with Geldart type B bulk material, three pertinent models were considered: Syamlal and O'Brien [34], Wen and Yu [35] and Gidaspow [36]. According to Min et al. [37], Gidaspow and Syamlal and O'Brien provide a good match between reality and simulation for fluidized bed gas-filling. Wen and Yu leads to a overestimation. Behjat et al. [38] reported good results for bed extension with the models by Gidaspow and Syamlal and O'Brien. Further, the model by Syamlal-O'Brian leads to an equal bubble formation and more realistic results [39]. The mathematical description of the governing equations and the three drag models are illustrated in Table 4. Moreover, the constitutive equations are shown in Table 5. 
Table 4. Governing equations.

\section{Conservation equations}

\section{Continuity equation}

$$
\frac{1}{\rho_{\mathrm{rq}}}\left(\frac{\partial}{\partial t}\left(\alpha_{\mathrm{q}} \rho_{\mathrm{q}}\right)+\nabla *\left(\alpha_{\mathrm{q}} \rho_{\mathrm{q}} \vec{v}_{\mathrm{q}}\right)=\sum_{p=1}^{n}\left(\dot{m}_{\mathrm{pq}}-\dot{m}_{\mathrm{qp}}\right)\right)
$$

\section{Energy equation}

$$
\begin{array}{r}
\frac{\partial}{\partial t}\left(\alpha_{\mathrm{q}} \rho_{\mathrm{q}} h_{\mathrm{q}}\right)+\nabla *\left(\alpha_{\mathrm{q}} \rho_{\mathrm{q}} \overrightarrow{v_{\mathrm{q}}} h_{\mathrm{q}}\right)=\alpha_{\mathrm{q}} \frac{\partial p_{q}}{\partial t}+\overline{\bar{\tau}}_{\mathrm{q}}: \nabla \vec{v}_{\mathrm{q}}-\overrightarrow{q_{\mathrm{q}}}+ \\
S_{\mathrm{q}}+\sum_{p=1}^{n}\left(Q_{p q}+\dot{m}_{\mathrm{pq}} h_{\mathrm{pq}}-\dot{m}_{\mathrm{qp}} h_{\mathrm{qp}}\right)
\end{array}
$$

Impulse equation

$$
\begin{array}{r}
\frac{\partial}{\partial t}\left(\alpha_{\mathrm{s}} \rho_{\mathrm{s}} \overrightarrow{v_{\mathrm{s}}}\right)+\nabla *\left(\alpha_{\mathrm{s}} \rho_{\mathrm{s}}{\overrightarrow{v_{\mathrm{s}}}}_{\vec{v}_{\mathrm{s}}}\right)=-\alpha_{\mathrm{s}} \nabla p-\nabla p_{\mathrm{s}}+\nabla \overline{\bar{\tau}}_{\mathrm{s}}+\alpha_{\mathrm{s}} \rho_{\mathrm{s}} \vec{g}+ \\
\sum_{p=1}^{N}\left(K_{\mathrm{ls}}\left(\vec{v}_{\mathrm{l}}-\vec{v}_{\mathrm{s}}\right)+\dot{m}_{\mathrm{ls}} \vec{v}_{\mathrm{ls}}-\dot{m}_{\mathrm{sl}} \vec{v}_{\mathrm{sl}}\right)+\left(\vec{F}_{\mathrm{s}}+\vec{F}_{\mathrm{lift}, \mathrm{s}}+\vec{F}_{\mathrm{vm}, \mathrm{s}}\right)
\end{array}
$$

Drag force

Drag models

$$
\begin{gathered}
K_{\mathrm{sl}}=\frac{\alpha_{\mathrm{s}} \rho_{\mathrm{s}} f}{\tau_{\mathrm{s}}} \\
\tau_{\mathrm{s}}=\frac{\rho_{\mathrm{s}} d_{\mathrm{s}}^{2}}{18 \mu_{1}}
\end{gathered}
$$

Syamlal and O'Brien [34]

$$
\begin{gathered}
f=\frac{C_{\mathrm{D}} R e_{\mathrm{s}} \alpha_{1}}{24 v_{\mathrm{r}, \mathrm{s}}^{2}} \\
C_{\mathrm{D}}=\left(0.63+\frac{4.8}{\sqrt{R e_{\mathrm{S}} / v_{\mathrm{r}, \mathrm{s}}}}\right)^{2} \\
v_{\mathrm{r}, \mathrm{s}}=0.5\left(A-0.06 e_{\mathrm{S}}=\frac{\rho_{\mathrm{l}}\left|\overrightarrow{v_{\mathrm{S}}}-\vec{v}_{1}\right| d_{\mathrm{s}}}{\mu_{1}}\right. \\
\left.+\sqrt{\left(0.06 \operatorname{Re}_{\mathrm{S}}\right)^{2}+0.12 \operatorname{Re} e_{\mathrm{S}}(2 B-A)+A^{2}}\right) \\
A=\alpha_{1}^{4.14} \\
B=\left\{\begin{array}{l}
0.8 \alpha_{1}^{1.28} \text { for } \alpha_{1} \leq 0.85 \\
\alpha_{1}^{2.65} \text { for } \alpha_{1}>0.85
\end{array}\right.
\end{gathered}
$$

Wen and Yu [35]

$$
\begin{gathered}
f=\frac{1}{24} C_{\mathrm{D}} R e_{\mathrm{S}} \alpha_{1}^{-2.64} \\
C_{\mathrm{D}}=\frac{24}{\alpha_{1} R e_{\mathrm{S}}}\left[1+0.15\left(\alpha_{1} R e_{\mathrm{S}}\right)^{0.687}\right]
\end{gathered}
$$

Gidaspow [36]

$$
f=\left\{\begin{array}{l}
\frac{1}{24} C_{\mathrm{D}} R e_{\mathrm{S}} \alpha_{1}^{-2.64} \text { for } \alpha_{1}>0.8 \\
150 \frac{\alpha_{\mathrm{S}}\left(1-\alpha_{1}\right) \mu_{1}}{\alpha_{1} d_{\mathrm{s}}^{2}}+1.75 \frac{\rho_{1} \alpha_{\mathrm{s}}\left|\vec{v}_{\mathrm{s}}-\vec{v}_{1}\right|}{d_{\mathrm{s}}} \text { for } \alpha_{1} \leq 0.8
\end{array}\right.
$$


Table 5. Constitutive equations.

\section{Constitutive equations}

Solids pressure [40]

$$
p_{\mathrm{s}}=\alpha_{\mathrm{s}} \rho_{\mathrm{s}} \Theta_{\mathrm{s}}+2 \rho_{\mathrm{s}}\left(1+e_{\mathrm{ss}}\right) \alpha_{\mathrm{s}}^{2} g_{0, \mathrm{ss}} \Theta_{\mathrm{s}}
$$

Granular bulk viscosity [40]

Granular shear viscosity

$$
\lambda_{\mathrm{s}}=\frac{4}{3} \alpha_{\mathrm{s}} \rho_{\mathrm{s}} d_{\mathrm{s}} g_{0, \mathrm{ss}}\left(1+e_{\mathrm{sS}}\right)\left(\frac{\Theta_{\mathrm{s}}}{\pi}\right)^{\frac{1}{2}}
$$

$$
\mu_{\mathrm{s}}=\mu_{\mathrm{s}, \mathrm{col}}+\mu_{\mathrm{s}, \mathrm{kin}}+\mu_{\mathrm{s}, \mathrm{fr}}
$$

Collisional viscosity

Kinetic viscosity

$$
\mu_{\mathrm{s}, \mathrm{col}}=\frac{4}{5} \alpha_{\mathrm{s}} \rho_{\mathrm{s}} d_{\mathrm{s}} g_{0, \mathrm{ss}}\left(1+e_{\mathrm{ss}}\right)\left(\frac{\Theta_{\mathrm{s}}}{\pi}\right)^{\frac{1}{2}} \alpha_{\mathrm{s}}
$$

Frictional viscosity [41]

$$
\mu_{\mathrm{s}, \mathrm{kin}}=\frac{10 \rho_{\mathrm{s}} d_{\mathrm{s}} \sqrt{\Theta_{\mathrm{s}} \pi}}{96 \alpha_{\mathrm{s}}\left(1+e_{\mathrm{ss}}\right) g_{0, \mathrm{ss}}}\left[1+\frac{4}{5} g_{0, \mathrm{ss}} \alpha_{\mathrm{s}}\left(1+e_{\mathrm{ss}}\right)\right]^{2} \alpha_{\mathrm{s}}
$$

Radial distribution [40]

$$
\mu_{\mathrm{s}, \mathrm{fr}}=\frac{p_{\mathrm{s}} \sin (\phi)}{2 \sqrt{I_{2 \mathrm{D}}}}
$$

Granular dissipation

$$
g_{0, \mathrm{ss}}=\left[1-\left(\frac{\alpha_{\mathrm{s}}}{\alpha_{\mathrm{s}, \max }}\right)^{\frac{1}{3}}\right]^{-1}
$$

$$
\gamma_{\Theta_{\mathrm{s}}}=\frac{12\left(1-e_{\mathrm{ss}}^{2}\right) g_{0, \mathrm{ss}}}{d_{\mathrm{s}} \sqrt{\pi}} \rho_{\mathrm{s}} \alpha_{\mathrm{s}}^{2} \Theta_{\mathrm{s}}^{\frac{3}{2}}
$$

\subsubsection{Heat Transfer}

The heat transfer coefficient describes the transferred heat from one phase to another and is therefore an important parameter in the numerical investigation [27]. However, the volumetric heat flow between both phases is given in Equations (36) and is composed of boundary surface, heat transfer coefficient and temperature difference:

$$
Q_{\mathrm{pq}}=h_{\mathrm{pq}} A_{\mathrm{i}}\left(T_{\mathrm{p}}-T_{\mathrm{q}}\right)
$$

This volumetric heat transfer coefficient was in turn a function of the Nusselt number and the bubble diameter:

$$
h_{\mathrm{pq}}=\frac{\kappa_{\mathrm{q}} N u_{\mathrm{p}}}{d_{\mathrm{p}}} .
$$

The heat transfer coefficient and the Nusselt number, respectively, was calculated using the model proposed by Gunn [42] (Equations (38) and (39)) and is valid for a porosity in the range of 0.35 to 1.0 and a wide range of the Reynolds number. The model by Gunn is commonly used in the literature $[38,43,44]$ for CFD simulations of bubbling fluidized beds with heat transfer.

$$
\begin{gathered}
N u_{\mathrm{s}}=\left(7-10 \alpha_{\mathrm{f}}+5 \alpha_{\mathrm{f}}^{2}\right)\left(1+0,7 \operatorname{Re}_{\mathrm{s}}^{0.2} \operatorname{Pr}^{1 / 3}\right)+\left(1.33-2.4 \alpha_{\mathrm{f}}+1.2 \alpha_{\mathrm{f}}^{2}\right) R e_{\mathrm{s}}^{0.7} \operatorname{Pr}^{1 / 3} \\
\operatorname{Pr}=\frac{\mathcal{c}_{\mathrm{p}, \mathrm{f}} \mu_{\mathrm{f}}}{\kappa_{\mathrm{f}}} .
\end{gathered}
$$




\subsubsection{Thermal Conductivity}

The model developed by Zehner and Schlünder [45] to describe the effective thermal conductivity of the gas-particle mix was further developed by Kuipers et al. [43]. It is often used in CFD simulations of heat transfers in fluidized beds [44,46,47]. The field of application for the equations developed by Zehner und Schlünder was extended to the dense phase of fluidized beds. The model used in this simulation refers to the description by Kuipers et al. [43]. The thermal conductivity of air was set to $\kappa_{g}=0.0265 \mathrm{~W} /(\mathrm{mK})$. The bulk material Lewatit ${ }^{\circledR}$ VP OC 1065 has factory made no thermal conductivity data. Hence, the thermal conductivity was chosen from an amorphous polystyrene with $\kappa_{s}=0.16 \mathrm{~W} /(\mathrm{mK})$. The effective thermal conductivity of the gas-particle mix as a function of the gas volume fraction $\alpha_{g}$ is shown in Figure 9.

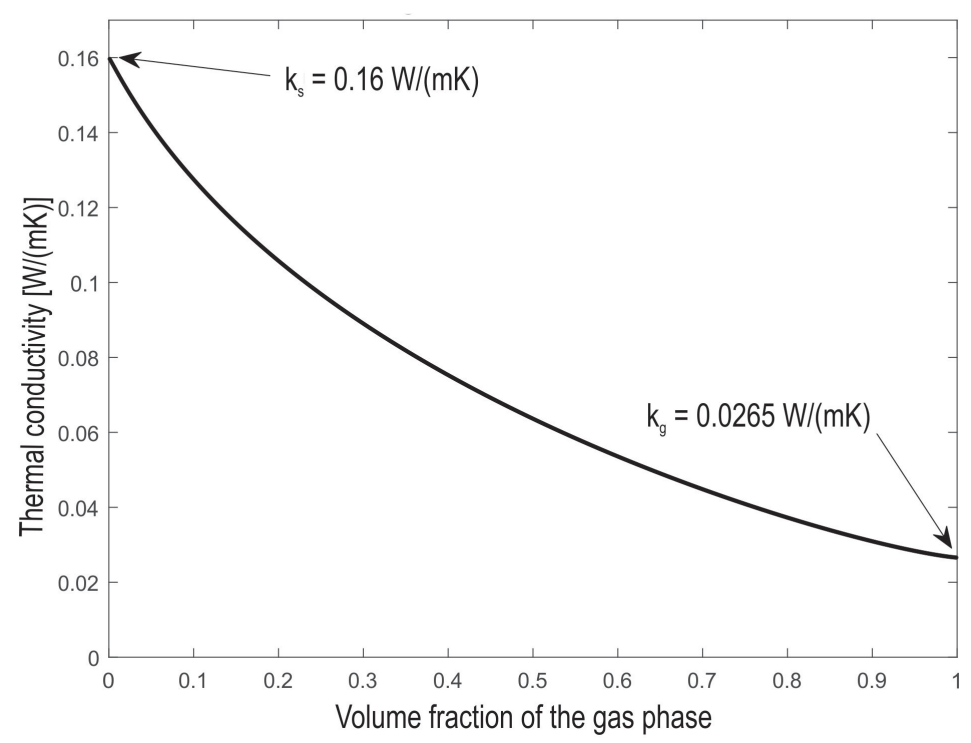

Figure 9. Effective thermal conductivity dependency on volume fraction of the gas phase by Kuipers et al. [43].

\subsubsection{Specularity Coefficient}

For the granular phase, the Euler-Euler model offers the possibility of a specularity coefficient $(\varphi)$, which represents slip velocity of solids at the wall in terms of the tangential momentum transfer due to collisions [27]. For specularity coefficient of 0 perfect specular collision at the wall can be assumed, 1 representing perfect diffuse collision [27,45]. The specularity coefficient model is used by most authors in the literature $[27,48]$. However, there is disagreement about the size of this coefficient. By Zhao et al. [49] a comparison was made between the recommendations of different authors and accordingly a standard specularity coefficient of $\varphi=0.05$ is used in this study.

\subsubsection{Implementation and Modelling}

In order to perform a CFD simulation, the test facility for the CFD model has been simplified. This is useful to optimize the mesh structure and further, to reduce the computational effort. In most cases a 3D simulation reproduces the physical behavior of the bubbling fluidized bed more realistically [37]. The same assessment was also made by Schreiber et al. [50]. In a fluidized bed simulation with immersed tubes it was discovered that in a 3D simulation larger bubbles occur with increasing bed height and decreasing bubble velocity. Furthermore, the influence of the wall can be better represented in the third dimension and thus, the three-dimensional simulation reflects the physical properties of the fluidization regime more accurately [50] and is therefore applied. 
The symmetry of the facility was exploited during model creation. The symmetry of the setup is shown in the Figure 10. The areas (A-I) are defined in the Figure 10 and listed in Table 6. The arrangement and dimensions of the tubes as well as the distance to the gas distributor are illustrated in Figure 11, equal to the test facility. The cross-sectional area of the bed was $0.1 \mathrm{~m} \times 0.2 \mathrm{~m}$ and the height is $1.07 \mathrm{~m}$. Initially, the bed was filled up to a height of $0.32 \mathrm{~m}$ with amine layered particle of diameter $650 \mu \mathrm{m}$. A volume fraction of the granulate of 0.6 is selected [45]. Air was introduced into the system at the bottom for fluidization with a constant velocity of $0.3 \mathrm{~m} / \mathrm{s}$. The solids circulation rate (SCR) was set to $0.013 \mathrm{~kg} / \mathrm{s}$, due to symmetry, half of the experimental SCR was set. The surface temperature $T_{\mathrm{HP}}$ of the heated tube wall (i.e., heating probe wall) was also set to $65^{\circ} \mathrm{C}(338 \mathrm{~K})$ as defined in the experimental part. It is assumed that minimal heat is emitted via the acrylic glass and therefore the heat flow via the wall is assumed to be adiabatic. A no-slip condition was set for the gas phase at all walls of the test facility surfaces. Figure 11 shows the initial and boundary conditions and Figure 12 the initial filling of the setup.

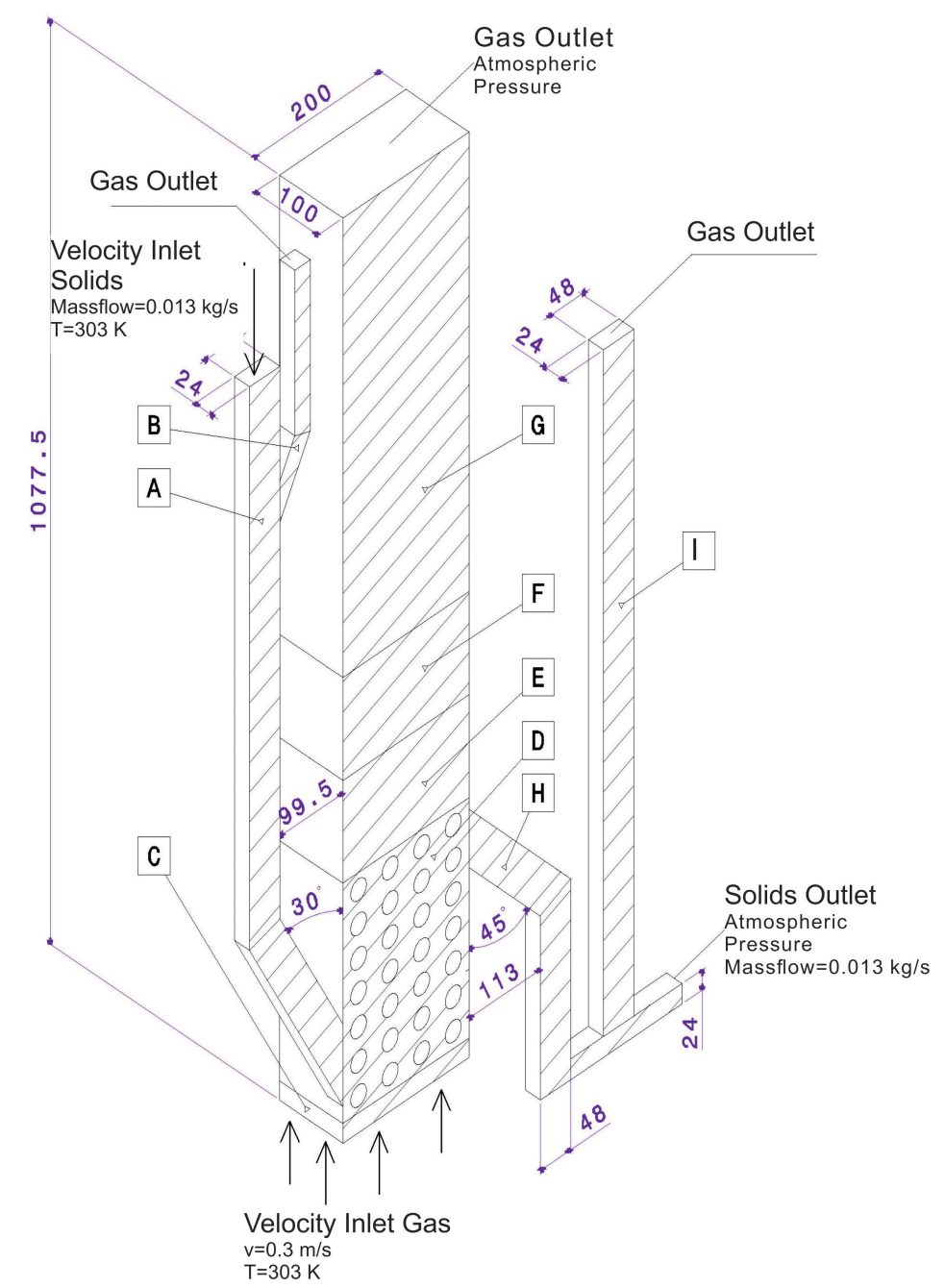

Figure 10. Schematic representation of the setup used in the simulations. 
Table 6. Units of the schematic setup.

\begin{tabular}{|c|c|}
\hline Unit & Description \\
\hline A & Inlet tube for solids \\
\hline $\mathrm{B}$ & Air outlet / Pressure compensation of the influence tube \\
\hline $\mathrm{C}-\mathrm{G}$ & Fluidized bed reactor \\
\hline $\mathrm{H}$ & Outlet tube for solids \\
\hline I & Constriction of the outlet tube \\
\hline
\end{tabular}

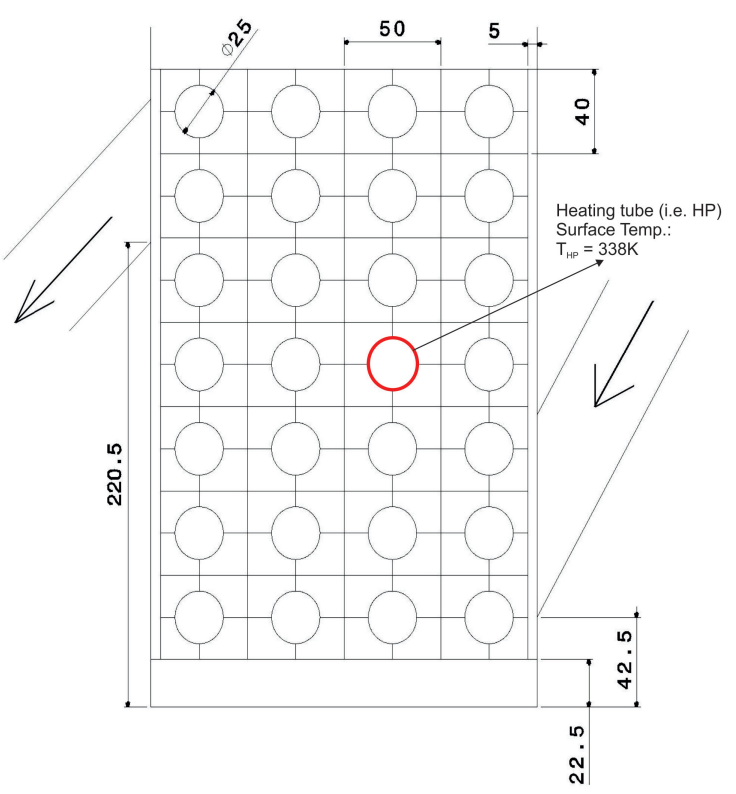

Figure 11. Geometry (given in $\mathrm{mm}$ ) of the tube arrangement.

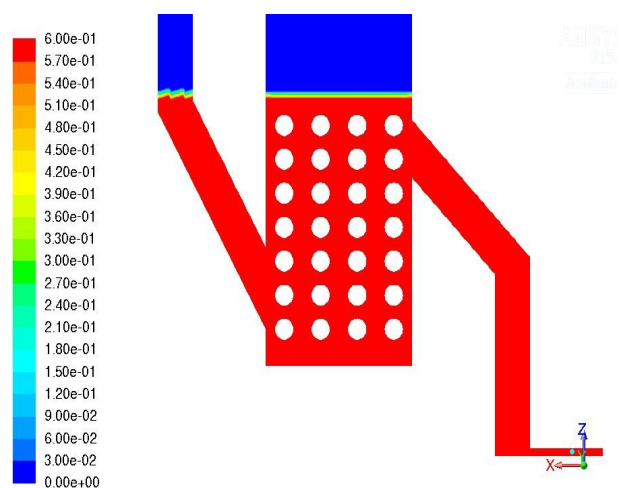

Figure 12. Initial volume fraction of the solids material with a packing fraction of 0.6.

In this work, the emerging fluidization regime and heat transfer coefficient for two different values of the specularity coefficient, two drag models and variation of the thermal conductivity were investigated. This can be used to determine which models and coefficient are suitable for accurate reproduction of the test facility. Hence, a standard model was defined with the basic settings and the prevailing equations as mentioned before due to a comparison reference. In addition to the standard model, new models were introduced for different thermal conductivity of the particle and thus a different effective thermal conductivity of the gas-particle mix (model II), specularity coefficient (model III) and drag model (model IV). A detailed definition of the models is given in Table 7. 
Table 7. Standard model and additional models.

\begin{tabular}{cccc}
\hline Model & Thermal Conductivity & Specularity Coefficient & Drag Model \\
\hline Standard model & $\kappa_{S}=0.16[\mathrm{~W} /(\mathrm{mK})]$ & $\varphi=0.05$ & Syamlal and O'Brien [34] \\
Model II & $\kappa_{S}=0.22[\mathrm{~W} /(\mathrm{mK})]$ & $\varphi=0.05$ & Syamlal and O'Brien [34] \\
Model III & $\kappa_{S}=0.16[\mathrm{~W} /(\mathrm{mK})]$ & $\varphi=0.5$ & Syamlal and O'Brien [34] \\
Model IV & $\kappa_{S}=0.16[\mathrm{~W} /(\mathrm{mK})]$ & $\varphi=0.05$ & Gidaspow [36] \\
\hline
\end{tabular}

Within the software environment the heat transfer coefficient $h_{F B}$ was determined using the Equation (40). The reference temperature $T_{\text {Ref }}$ can be freely chosen, the tube wall temperature $T_{\mathrm{HP}}$ is given by the boundary condition and the heat flux density $\dot{q}$ is calculated by the software. The reference temperature $T_{\mathrm{Ref}}$, equal to the experimental $T_{\mathrm{FB}}$, is set to $303 \mathrm{~K}$ due to the pseudo stationary temperature of the fluidized bed determined by the experiment.

$$
h_{F B}=\frac{\dot{q}}{T_{\mathrm{HP}}-T_{\mathrm{Ref}}}
$$

\subsubsection{Simulation Processing}

The CFD tool ANSYS ${ }^{\circledR}$ Fluent ${ }^{\circledR}$ comprises well known discretization schemes $[37,51-53]$ and has been used in order of exactly representing the different flow characteristics. For solving the constitutive equations additional mathematical boundary conditions (i.e., Dirichlet, Neumann and Cauchy) are needed due to resulting constants of the differential equations. In this simulation study the phase-coupled SIMPLE algorithm was used [27,54]. The Euler-Euler method requires that the cell size be larger than the particle diameter or the average distance between two particles. Therefore, Celmins [55] developed an empirical relationship between the particle diameter, the expected average gas content and the required minimum mesh size and thus it was applied in this study. Based on the Celmins [55] mesh size calculation, the mesh size was designed with $4 \mathrm{~mm}$. Furthermore, the mesh size was designed with $2.7 \mathrm{~mm}$ near tube surrounding area due to reproduce the heat transfer coefficient on the heated tube better and to meet the conditions of the Euler-Euler method. Due to bubble formation within a fluidized bed, none steady state solution can be assumed. Thus, a transient simulation with determination of passable time steps, has to be done. The simulations were executed for a period of $80 \mathrm{~s}$. The step size of $1 \cdot 10^{-4} \mathrm{~s}$ has been chosen to avoid possible unstable performance during the start-up phase of the simulation. After critical start-up phase, the step size was raised to $2 \cdot 10^{-4} \mathrm{~s}$. Also a stricter convergence criterion of $1 \cdot 10^{-4}$ was used [37].

\subsection{Numerical Results and Discussion}

\subsubsection{Fluidization Regime}

In this work qualitative optical criteria like bed extension, position of the appearing bubble, bubble size and bubble form were used to assess the simulated fluidization regime. The validation was obtained by comparing the simulated fluidization regime with the experimental observed fluidization regime. The fluidization regime equilibrium of the simulation has set itself within a second. The achieved bed extension of the simulation was immediately identical to that of the experiment. The time mean void fraction is approximately at 0.47 .

Figure 13 shows the solids fraction distribution in the bed for the standard model, model III and model IV after $0.6 \mathrm{~s}$ and $5 \mathrm{~s}$ of real-time simulation. The aim was to define the best drag model and specularity coefficient for the numerical simulation of a bubbling fluidized bed. Furthermore, model II has been no impact to the fluidization regime. 


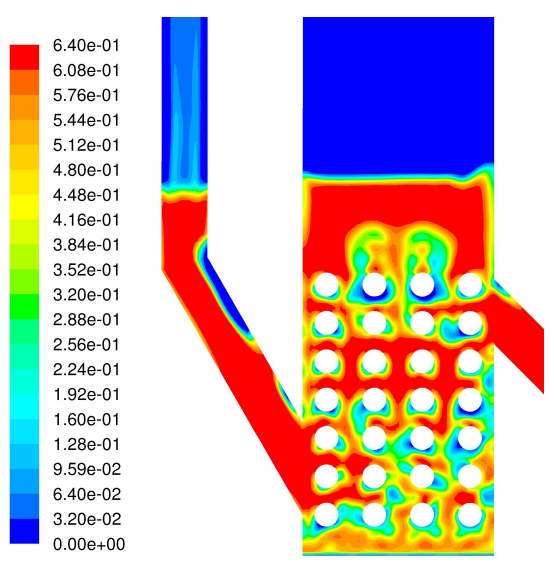

(a) Standard model $-0.6 \mathrm{~s}$

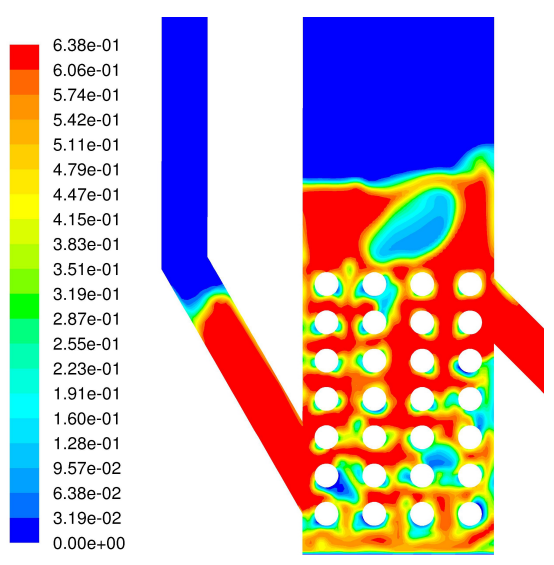

(d) Standard model $-5 \mathrm{~s}$

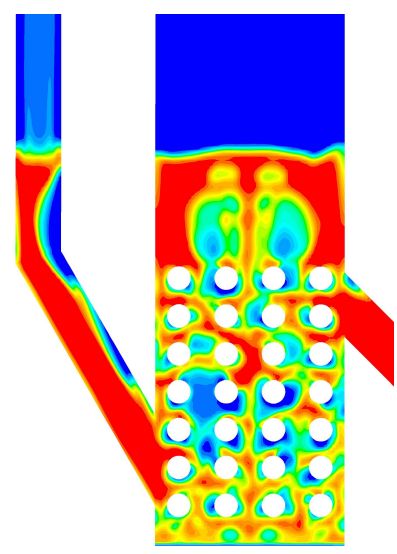

(b) Model IV—-0.6 s

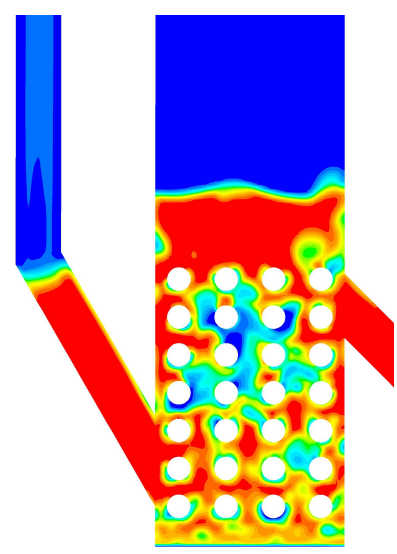

(e) Model IV- $5 \mathrm{~s}$

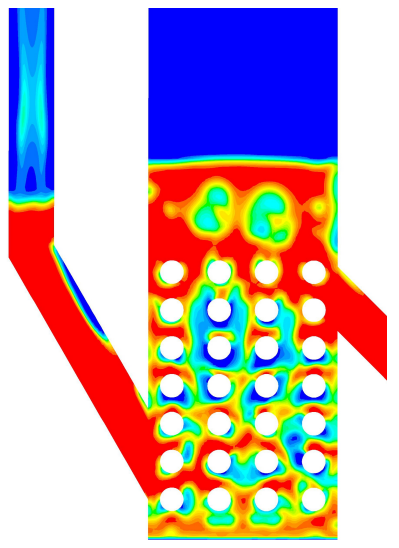

(c) Model III $-0.6 \mathrm{~s}$

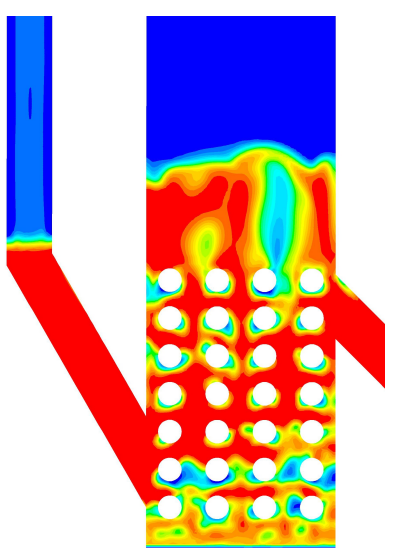

(f) Model III-5 s

Figure 13. Comparison of fluidization regimes after $0.6 \mathrm{~s}$ and $5 \mathrm{~s}$ real time simulation.

The bed extension in the standard model is about two tube rows high and varied slightly due to heavy bubbling conditions. The bed surface exhibited a clear contour and phase boundary. The bubbles appeared in the space between gas distribution plate and the lowest tube row. The bubbles moved around the immersed tubes and can be split or combined with other bubbles after passing through the tube. Further, some bubble movement existed upward along the wall surface. The bubble size can vary along the fluidized bed height. In the bottom area small bubbles occur equally distributed over the the bed. With increasing distance to the bottom the bubble size increases. The bubble shape depends on the located position of the bubble within the fluidized bed. The bubbles located near the bottom were often flattened, afterwards, forming an open-top ring around the tubes. Near the top area the bubble becomes a bell shaped contour.

The bed extension by model IV is similar to the standard model but strong fluctuation behaviors can be observed. The fluidized bed surface had a less clear contour and even splashing particles occurred. The bubbles are greater, irregular and show a much faster movement within the fluidized bed (Figure 13b,e).

The use of model III led to a slightly higher bed extension compared to the other two models, but the bed surface is similar to the standard model. Furthermore, the bubble movement around the tubes is faster. Bubbles occur bigger in the bottom area (Figure 13c,f). The higher specularity coefficient influences the hydrodynamics of the fluidized bed in terms of greater bubble formation.

As mentioned before, the fluidization regime equilibrium of the simulation was set immediately, thus for the regime validation the times $2 \mathrm{~s}$ and $4 \mathrm{~s}$ were chosen. The selected times of the experiment are those at which the test facility is in operation and a fluidization regime set. Figure 14 compares optical 
with the named criteria above the numerical results with the experimental results. The numerical results in Figure 14 are illustrated by the standard model and model IV at different time steps. The experimental results show a much stronger splashing of the solids material at the bed surface compared to the simulation with model IV. The different letters marked the approximately equal fluidization regimes. The mark B shows the best accordance between numerical and experimental investigations. The characteristic bubble shape and size can be observed under the immersed tube.

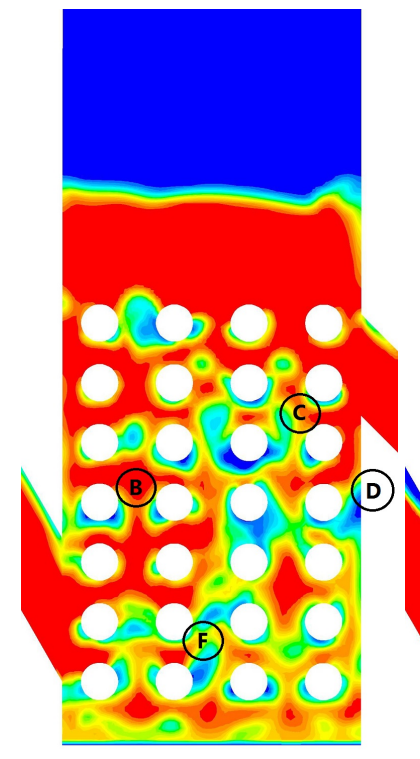

(a) Standard model-2 $\mathrm{s}$

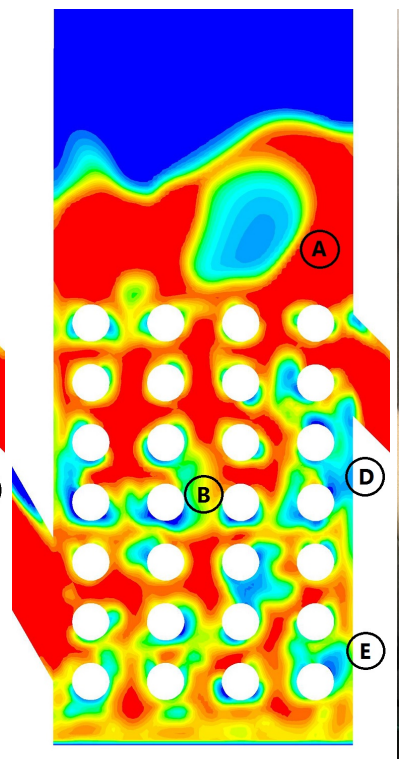

(b) Model IV—4 s

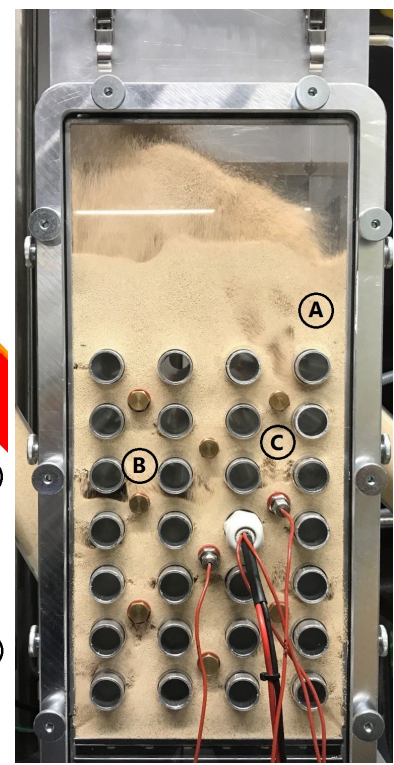

(c) Experimental-Time 1

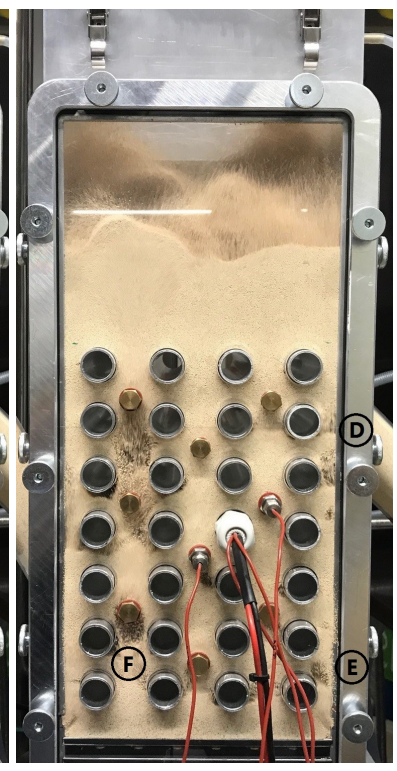

(d) Experimental-Time 2

Figure 14. Numerical fluidization regime compared to experimental fluidization regime. A: Big bubble formation in the upper area of the bed; B: characteristic bubble shape and size under the immersed tube; C: bubble at the dissolving process at the tube; D: appearing bubble near wall area located on outlet side (upper area); E: appearing bubble near wall area located on outlet side (lower area); F: bubble between tubes.

The fluidization regime (bed expansion and bubble characteristic) can be well reproduced in a dense bed using the Euler-Euler method. The behavior of the bed surface (splashes, no clear phase boundaries due to swirling particles) can be rudimentary represented with the model IV. However, the Gidaspow model, as used in model IV, is largely applied in fluidized bed studies and it was chosen owing to its accuracy in predicting good hydrodynamic representation of the bed. Furthermore, there is still no agreement about the best specularity coefficient value for use in fluidized bed simulations and therefore, it has to be validated for each individual case $[27,56]$.

\subsubsection{Heat Transfer Rates within the Fluidization Regime}

First of all, it can be assumed that the heat transfer coefficient remains constant while a thermodynamic equilibrium is achieved and afterwards. The heat transfer coefficients were calculated between $5 \mathrm{~s}$ and $80 \mathrm{~s}$ of simulation for the different models (Table 7). The average heat transfer coefficients between immersed tube wall and fluidized bed are illustrated in Table 8. The Table 9 displays maximum and minimum computed heat transfer coefficients of the simulation compared to experimental results and used established literature models from the experimental part. 
Table 8. Comparison of average heat transfer coefficient $h_{F B}$.

\begin{tabular}{lcccc}
\hline Model & $\boldsymbol{h}_{\boldsymbol{F B}}\left[\frac{\mathrm{W}}{\mathrm{m}^{2} \mathrm{~K}}\right]$ & Experimental & Natusch et al. & Molerus et al. \\
\hline Standard model & 85.2 & $-57.2 \%$ & $-38.1 \%$ & $-49.0 \%$ \\
Model II & $94.1(+10.4 \%)$ & $-52.7 \%$ & $-31.6 \%$ & $-43.7 \%$ \\
Model III & $88.4(+3.8 \%)$ & $-55.6 \%$ & $-35.8 \%$ & $-47.1 \%$ \\
Model IV & $85.4(+0.2 \%)$ & $-57.1 \%$ & $-37.9 \%$ & $-48.9 \%$ \\
Experimental $\left(0.3 \frac{\mathrm{m}}{\mathrm{s}}\right)$ & 199 & - & - & - \\
Natusch et al. & 137.6 & $-30.9 \%$ & - & - \\
Molerus et al. & 167 & $-16.1 \%$ & - & - \\
\hline
\end{tabular}

Table 9. Comparison of maximal/minimal heat transfer coefficient $h_{F B}$.

\begin{tabular}{ccccc}
\hline Model & $\boldsymbol{h}_{\boldsymbol{F B}}\left[\frac{\mathbf{W}}{\mathbf{m}^{2} \mathbf{K}}\right]$ & Experimental & Natusch et al. & Molerus et al. \\
\hline Standard model max. & 112 & $-43.7 \%$ & $-18.6 \%$ & $-32.9 \%$ \\
Standard model min. & 67 & $-66.3 \%$ & $-51.3 \%$ & $-59.9 \%$ \\
Model II max. & $122(+8.9 \%)$ & $-38.7 \%$ & $-11.3 \%$ & $-26.9 \%$ \\
Model II min. & $62(-7.5 \%)$ & $-68.8 \%$ & $-54.9 \%$ & $-62.9 \%$ \\
Model III max. & $111(-0.9 \%)$ & $-44.2 \%$ & $-19.3 \%$ & $-33.5 \%$ \\
Model III min. & $65(-3 \%)$ & $-67.3 \%$ & $-52.8 \%$ & $-61.1 \%$ \\
Model IV max. & $108(-3.6 \%)$ & $-45.7 \%$ & $-21.5 \%$ & $-35.3 \%$ \\
Model IV min. & $62(-7.5 \%)$ & $-68.8 \%$ & $-54.9 \%$ & $-62.9 \%$ \\
Experimental $\left(0.3 \frac{\mathrm{m}}{\mathrm{s}}\right)$ & 199 & - & - & - \\
Natusch et al. & 137.6 & $-30.9 \%$ & - & - \\
Molerus et al. & 167 & $-16.1 \%$ & - & - \\
\hline
\end{tabular}

In addition, the CFD simulation was used to obtain a more detailed understanding of the behavior of the local heat transfer coefficient at the heating tube. Figure 15 illustrates the local heat transfer coefficient $h_{L}$ on the heating tube wall with the associated solids fraction. It can be seen that areas with a high solids fraction the heat coefficient also reaches high values. The maximum values, however, often appear in the transition region of solid and gas phase. Furthermore, in the case of constant solid volume fraction distribution, the maximum heat transfer coefficient appears at maximum volume fraction.

Tables 8 and 9 show that the thermal conductivity (model II) of the material and the adjustment of the specularity coefficient (model III) effects the heat transfer coefficient in the real time simulation. According to Bisognin et al. [27] the influence of the specularity coefficient parameter on the heat transfer coefficient between fluidized bed and a heated surface immersed in the bubbling bed has not been studied well in literature. Therefore, the specularity coefficient needs to be further investigated in terms of heat transfer. Changing the drag model from Syamlal-O'Brien to Gidaspow does not significantly change the heat transfer coefficient. However, the heat transfer coefficient calculated by the simulation is of the same scale, but shows quantitatively significant deviations from the experiment and the correlations. Possible causes for the deviation of the heat transfer coefficient between experiment and numerical simulation are:

- Material properties:

The comparison between the different models (Table 8) shows that material properties, especially thermal conductivity, have a large influence on the heat transfer coefficient. Other material properties like the Sauter mean diameter distribution of the particles can improve the heat transfer coefficient as well. Furthermore, electrostatic charges of the particles can play a major role that cannot be modeled.

- Modeling aspects:

The variation of the specularity coefficient causes a change of the heat transfer coefficient and thus, strongly influences the occurring heat transfer in the computational fluidized bed. However, the influence of the drag model on these phenomena is negligible. A variation of the friction parameters was not considered. 
- Euler-Euler method:

The suitability of the Euler-Euler method for accurately determining the heat transfer coefficient was not confirmed. It is not sufficient to model the global fluidization regime with the help of the CFD, but the conditions in the immediate surroundings of the tube must be represented in terms of volume fraction, phase velocity, residence time and particle mixing. The mesh fineness on the heated tube is governed by the condition of the Euler-Euler method of volume determination. To ensure the validity of the volume determination, the mesh cell size must not be less than a minimum. This leads to the fact that the representation of the heat transfer coefficient on the heated tube by the volume determination is not sufficient and a higher network resolution would be required. But this contradicts the Euler-Euler model.

- Thermodynamic equilibrium:

Due to the high calculation effort ( $1 \mathrm{~s}$ simulation time $\sim 12 \mathrm{~h}$ calculation time) no thermodynamic equilibrium could be reached. This occurs in the experiment after approx. $10 \mathrm{~min}$, but only a maximum of $80 \mathrm{~s}$ were simulated but should have no influence on the heat transfer coefficient.

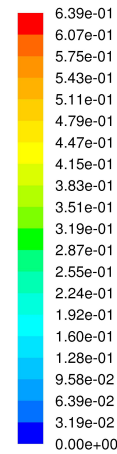

(a) Volume fraction (solids) at $50.00 \mathrm{~s}$
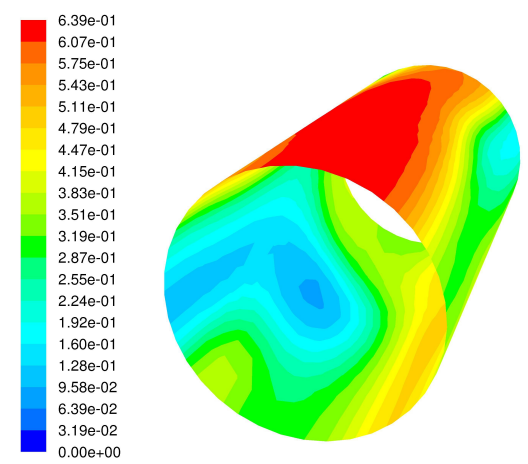

(c) Volume fraction (solids) at $50.08 \mathrm{~s}$
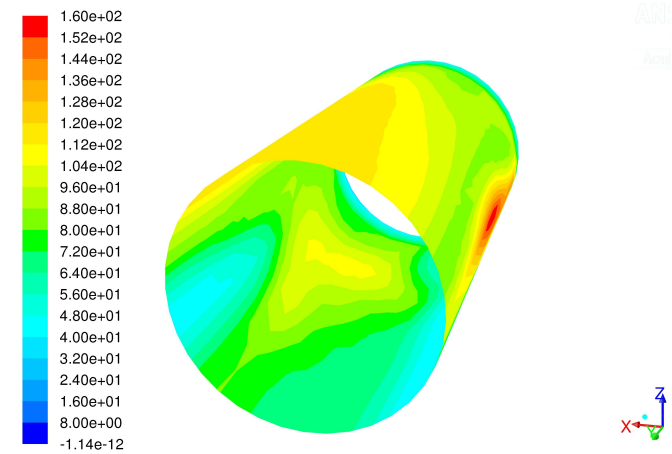

(b) Heat transfer coefficient $h_{L} \mathrm{~W} /\left(\mathrm{m}^{2} \mathrm{~K}\right)$ at $50.00 \mathrm{~s}$
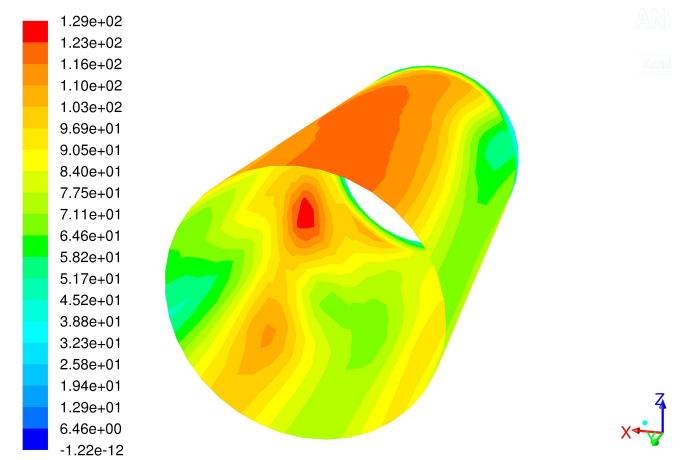

(d) Heat transfer coefficient $h_{L} \mathrm{~W} /\left(\mathrm{m}^{2} \mathrm{~K}\right)$ at $50.08 \mathrm{~s}$

Figure 15. Locale heat transfer coefficient on outer heating tube wall (i.e., heating probe).

\section{Conclusions}

The experimental investigations on heat transfer within a bubbling fluidized bed test facility with Geldart type B amine bulk material showed that, the single bare tube with $25 \mathrm{~mm}$ outer diameter have approximately equal measured results as both tube bundle arrangements. Moreover, in-line and staggered configuration also have identical HTCs which contradicts the finding that staggered have overall slightly higher HTCs than in-line layouts. This could only be determined in the last third of the measurement. In the same way, single tubes should have significantly higher HTCs.

In order to predict heat transfer coefficients when it comes to dimensioning for TSA heat exchangers, the model proposed by Molerus et al. [21,22] applied with the tube diameter factor 
by Petrie et al. [11] are in a good agreement with the obtained experimental results. Nevertheless, the comparison of the experimentally obtained data with tube bundle modeled data point out, that the literature models are not able to describe the experimental results. The usability of the mathematical models depends, as shown in the evaluation, on the particle properties. For this reason, it is unclear which model can be used to dimension TSA processes for optimal heat integration. Thus, future experimental series with the introduced fluidized bed test facility will be conducted with different heat exchanger layouts, other tube diameters and finned tubes for heat transfer measurements.

A numerical study has been done of the test facility in terms of fluidization regime and heat transfer coefficient investigations. This work used the Euler-Euler method to describe the multiphase system. For a flow mechanical and thermal modeling of granular multiphase flows by CFD it is necessary to model the particle properties as well as the interaction forces between gas and solids very precisely. In order to obtain a more accurate representation of the fluidized bed at the bed surface in the dilute regime, it may be necessary to consider the diameter distribution of the particles or to use a modified drag model which uses experimentally determined values. Anyway, this tool can be used for modeling regimes of a fluidized bed TSA-reactor with external circulation.

For a more accurate determination of the heat transfer coefficient, the influencing factors on it must be identified. Since the thermal conductivity of both phases has a large influence on it, the modeling should be checked according to Zehner und Schlünder and adapted if necessary.

Further investigations of the particle properties can help to improve the modeling of the multiphase system with Euler-Euler. The interaction between gas and solids can possibly be improved using modified drag models. The effects of a mesh refinement on the tube, which contradicts the Euler-Euler approach, should be considered with regard to the effects on the fluidization regime and heat transfer. A numerical analysis with an alternative software (i.e., OPENFOAM ${ }^{\circledR}$ ) can also help to classify the results. Nevertheless, the first step for the development of a simulation was taken for TSA-applications.

Author Contributions: Conceptualization, R.H.; Formal analysis, H.V.; Investigation, H.V. and D.P.; Methodology, H.V., D.P. and R.H.; Supervision, R.H.; Validation, D.P.; Writing-original draft, H.V. and D.P.

Funding: The authors appreciate the financial support by the Austrian Climate and Energy Fund (FFG project no. 853612).

Acknowledgments: Open Access Funding by TU Wien. The authors want to thank Nathalie Garcia, who contributed a great deal of work in conducting and analyzing the experimental part.

Conflicts of Interest: The authors declare no conflicts of interest.

\section{Abbrevations}

CFD Computer fluid dynamics

TSA Temperature swing adsorption

FB Fluidized bed

HP Heating probe

HTC Heat transfer coefficient

SCR Solids circulation rate

ST Single tube

TB Tube bundle

\section{Index}

f fluid phase

g gas phase

1 liquid phase

$\mathrm{mf}$ minimum fluidization

pq phase $p$ phase $q$

$\mathrm{s}$ solids phase 


\section{Symbols}

$\begin{array}{lll}A & \text { Surface area } & {\left[\mathrm{m}^{2}\right]} \\ \mathrm{Ar} & \text { Archimedes number } & {[1]} \\ d_{t} & \text { Tube diameter } & {[\mathrm{m}]} \\ \mathrm{C}_{\mathrm{D}} & \text { Drag coefficient } & {[-]} \\ \mathrm{c}_{\mathrm{p}} & \text { Specific heat capacity } & {[\mathrm{J} /(\mathrm{kgK})]} \\ \mathrm{e}_{\mathrm{ss}} & \text { Collision factor } & {[-]} \\ \mathrm{F} & \text { Correct value/determined function } & {[-]} \\ \mathrm{f}_{\mathrm{i}} & \text { Measured value } & {[-]} \\ \mathrm{f} & \text { Drag function } & {[-]} \\ \mathrm{f} & \text { Heat exchanger factor } & {[-]} \\ \mathrm{g}_{0, s s} & \text { Radial distribution function } & {[-]} \\ \mathrm{h} & \text { Heat transfer coefficient } & {\left[\mathrm{W} /\left(\mathrm{m}^{2} \mathrm{~K}\right)\right]} \\ \mathrm{h}_{\mathrm{L}} & \text { Locale heat transfer coefficient } & {\left[\mathrm{W} /\left(\mathrm{m}^{2} \mathrm{~K}\right)\right]} \\ \mathrm{h}_{\mathrm{gc}} & \text { Gas convective heat transfer coefficient } & {\left[\mathrm{W} /\left(\mathrm{m}^{2} \mathrm{~K}\right)\right]} \\ \mathrm{h}_{\mathrm{pc}} & \text { particle convective heat transfer coefficient } & {\left[\mathrm{W} /\left(\mathrm{m}^{2} \mathrm{~K}\right)\right]} \\ \mathrm{h}_{\text {rad }} & \text { Radiation heat transfer coefficient } & {\left[\mathrm{W} /\left(\mathrm{m}^{2} \mathrm{~K}\right)\right]} \\ \mathrm{I} & \text { Current } & {[\mathrm{A}]} \\ \mathrm{K}_{\mathrm{sl}} & \text { Interaction coefficient between solids and liquid phase } & {[-]} \\ \mathrm{m} & \text { Mass flow } & {[\mathrm{kg} / \mathrm{s}]} \\ \mathrm{Nu} & \text { Nusselt number } & {[1]} \\ \mathrm{P}_{\mathrm{el}} & \text { Electrical power } & {[\mathrm{W}]} \\ \mathrm{p} & \text { Pressure } & {[\mathrm{Pa}]} \\ \mathrm{p}_{\text {diag }} & \text { Diagonal geometry } & {[\mathrm{mm}]} \\ \mathrm{p}_{\mathrm{h}} & \text { Horizontal geometry } & {[\mathrm{mm}]} \\ \mathrm{p}_{\text {min }} & \text { Minimal geometry } & {[\mathrm{mm}]} \\ \mathrm{p}_{\mathrm{v}} & \text { Vertical geometry } & {[\mathrm{mm}]} \\ \mathrm{Pr} & \text { Prandtl number } & {[1]} \\ \dot{Q} & \text { Heat flow } & {[\mathrm{W}]} \\ \mathrm{Re} & \text { Reynolds number } & {[1]} \\ \mathrm{s}_{\mathrm{h}} & \text { Horizontal spacing } & {[\mathrm{mm}]} \\ \mathrm{s}_{\text {diag }} & \text { Diagonal spacing } & {[\mathrm{mm}]} \\ \mathrm{T} & \text { Temperature } & {[\mathrm{K}]} \\ \mathrm{u} & \text { Velocity } & {[\mathrm{m} / \mathrm{s}]} \\ \mathrm{U} & \text { Voltage } & {[\mathrm{V}]} \\ \vec{v}_{\mathrm{q}} & \text { Velocity vector of phase q } & {[\mathrm{m} / \mathrm{s}]} \\ & & \\ & & \end{array}$

\section{Greek Symbols}

$\begin{array}{lll}\alpha & \text { Volume fraction } & {[-]} \\ \gamma \Theta_{\mathrm{s}} & \text { Dissipation of energy due to collision } & {\left[\mathrm{W} / \mathrm{m}^{3}\right]} \\ \Delta t & \text { Time step } & {[\mathrm{s}]} \\ \epsilon & \text { Porosity of fluidized bed } & {[-]} \\ \Theta_{\mathrm{s}} & \text { Granulate temperature } & {\left[\mathrm{m}^{2} / \mathrm{s}^{2}\right]} \\ \kappa & \text { Thermal conductivity } & {[\mathrm{W} /(\mathrm{mK})]} \\ \lambda_{\mathrm{q}} & \text { Volume viscosity of phase } \mathrm{q} & {[\mathrm{kg} /(\mathrm{ms})]} \\ \mu & \text { Dynamic viscosity } & {[\mathrm{kg} /(\mathrm{ms})]} \\ \rho & \text { Density } & {\left[\mathrm{kg} / \mathrm{m}^{3}\right]} \\ \overline{\bar{\tau}}_{\mathrm{q}} & \text { Stress tensor } & {\left[\mathrm{N} / \mathrm{m}^{2}\right]} \\ \tau_{\mathrm{q}} & \text { Particle relaxation time } & {[-]} \\ \varphi & \text { Specularity coefficient } & {[-]}\end{array}$

\section{References}

1. Mondino, G.; Grande, C.A.; Blom, R. Effect of gas recycling on the performance of a moving bed temperature-swing (MBTSA) process for $\mathrm{CO}_{2}$ capture in a coal fired power plant context. Energies 2017, 10, 745. [CrossRef]

2. Vogtenhuber, H.; Hofmann, R.; Helminger, F.; Schöny, G. Process simulation of an efficient temperature swing adsorption concept for biogas upgrading. Energy 2018, 162, 200-209. [CrossRef] 
3. Marx, D.; Joss, L.; Hefti, M.; Mazzotti, M. Temperature swing adsorption for postcombustion $\mathrm{CO}_{2}$ capture: Single- and multicolumn experiments and simulations. Ind. Eng. Chem. Res. 2016, 55, 1401-1412. [CrossRef]

4. Yang, W.C.; Hoffman, J. Exploratory design study on reactor configurations for carbon dioxide capture from conventional power plants employing regenerable solid sorbents. Ind. Eng. Chem. Res. 2009, 48, 341-351. [CrossRef]

5. Blaszczuk, A.; Nowak, W.; Krzywanski, J. Effect of bed particle size on heat transfer between fluidized bed of group b particles and vertical rifled tubes. Powder Technol. 2017, 316, 111-122. [CrossRef]

6. Blaszczuk, A.; Pogorzelec, M.; Shimizu, T. Heat transfer characteristics in a large-scale bubbling fluidized bed with immersed horizontal tube bundles. Energy 2018, 162, 10-19. [CrossRef]

7. Zabrodsky, S.S. Hydrodynamics and Heat Transfer in Fluidized Beds; MIT Press: Cambridge, MA, USA, 1966.

8. Stefanova, A.; Bi, H.T.; Lim, C.J.; Grace, J.R. Heat transfer from immersed vertical tube in a fluidized bed of group A particles near the transition to the turbulent fluidization flow regime. Int. J. Heat Mass Transf. 2008, 51, 2020-2028. [CrossRef]

9. Vreedenberg, H.A. Heat transfer between a fluidized bed and a horizontal tube. Chem. Eng. Sci. 1958, 9, 52-60. [CrossRef]

10. Verma, V.; Li, T.; Dietiker, J.F.; Rogers, W.A. Hydrodynamics of gas-solids flow in a bubbling fluidized bed with immersed vertical U-tube banks. Chem. Eng. J. 2016, 287, 727-743. [CrossRef]

11. Petrie, J.C.; Freeby, W.A.; Buckham, J.A. In-Bed Heat Exchangers. Chem. Eng. Prog. 1968, 7, 45-51.

12. Noack, R. Lokaler Wärmeübergang an horizontalen Rohren in Wirbelschichten. Chemie Ingenieur Technik 1970, 42, 371-376. [CrossRef]

13. Geldart, D. Types of gas fluidization. Powder Technol. 1973, 7, 285-292. [CrossRef]

14. Schöny, G.; Zehetner, E.; Fuchs, J.; Pröll, T.; Sprachmann, G.; Hofbauer, H. Design of a bench scale unit for continuous $\mathrm{CO} 2$ capture via temperature swing adsorption-Fluid-dynamic feasibility study. Chem. Eng. Res. Des. 2016, 106, 155-167. [CrossRef]

15. Werther, J. Fluidized-Bed Reactors: Handbook of Heterogeneous Catalysis; Wiley-VCH Verlag GmbH \& Co. KGaA: Weinheim, Germany, 2008;

16. Fan, L.S.; Zhu, C. Principles of Gas-Solid Flows: Cambridge Seris in Chmeical Engineering; Cambridge University Press: Cambridge, UK, 1998.

17. Błaszczuk, A.; Krzywański, J. A comparison of fuzzy logic and cluster renewal approaches for heat transfer modeling in a $1296 \mathrm{t} / \mathrm{h}$ CFB boiler with low level of flue gas recirculation. Arch. Thermodyn. 2017, 38, 91-122. [CrossRef]

18. Karimipour, S.; Zarghami, R.; Mostoufi, N.; Sotudeh-Gharebagh, R. Evaluation of heat transfer coefficient in gas-solid fluidized beds using cluster-based approach. Powder Technol. 2007, 172, 19-26. [CrossRef]

19. Dutta, A.; Basu, P. An improved cluster-renewal model for the estimation of heat transfer coefficients on the furnace walls of commercial circulating fluidized bed boilers. J. Heat Transf. 2004, 126, 1040-1043. [CrossRef]

20. Zarghami, R.; Mostoufi, N.; Sotudeh-Gharebagh, R. Probabilistic approach to particle-wall contact time in fluidized beds. J. Heat Transf. 2009, 131. [CrossRef]

21. Molerus, O.; Burschka, A.; Dietz, S. Particle migration at solid surfaces and heat transfer in bubbling fluidized beds-I. Particle migration measurement systems. Chem. Eng. Sci. 1995, 50, 871-877. [CrossRef]

22. Molerus, O.; Burschka, A.; Dietz, S. Particle migration at solid surfaces and heat transfer in bubbling fluidized beds-II. Prediction of heat transfer in bubbling fluidized beds. Chem. Eng. Sci. 1995, 50, 879-885. [CrossRef]

23. Natusch, H.J.; Neukirchen, B.; Noack, R. Lokale Wärmeübergangszahlen für ein Einzelrohr und für Rohrbündel Verschiedener Anordnung in Wirbelschichten; Schlussbericht, GVT-Bericht; Forschungs-Gesellschaft Verfahrenstechnik e.V. (GVT): Frankfurt am Main, Germany, 1975.

24. Martin, H. Wärmeübergang in Wirbelschichten: VDI-Wärmeatlas, 2nd ed.; VDI-Buch, Springer-Verlag: Berlin/Heidelberg, Germany, 2010.

25. Lechner, S.; Merzsch, M.; Krautz, H.J. Heat-transfer from horizontal tube bundles into fluidized beds with Geldart A lignite particles. Powder Technol. 2014, 253, 14-21. [CrossRef]

26. Hofer, G.; Schöny, G.; Fuchs, J.; Pröll, T. Investigating wall-to-bed heat transfer in view of a continuous temperature swing adsorption process. Fuel Process. Technol. 2017, 169, 157-169. [CrossRef]

27. Bisognin, P.C.; Fusco, J.M.; Soares, C. Heat transfer in fluidized beds with immersed surface: Effect of geometric parameters of surface. Powder Technol. 2016, 297, 401-408. [CrossRef] 
28. Yang, W.C. Handbook of Fluidization and Fluid-Particle Systems; Chemical Industries, Taylor \& Francis: Abingdon, UK, 2003.

29. Sonnleitner, E.; Schöny, G.; Hofbauer, H. Assessment of zeolite $13 \mathrm{X}$ and Lewatit $囚$ VP OC 1065 for application in a continuous temperature swing adsorption process for biogas upgrading. Biomass Convers. Biorefinery 2017, 8, 267. [CrossRef]

30. Hofbauer, H. Wirbelschichttechnik, Unterlagen zur Vorlesung 159.220, SS 2012, 6. Auflage, TU Wien. Available online: https: / / tiss.tuwien.ac.at/ course/ courseDetails.xhtml?dswid=9861\&dsrid=114\& courseNr=159220\&semester $=2018$ S (accessed on 10 July 2019).

31. Huilin, L.; Gidaspow, D.; Bouillard, J.; Wentie, L. Hydrodynamic simulation of gas-solid flow in a riser using kinetic theory of granular flow. Chem. Eng. J. 2003, 95, 1-13. [CrossRef]

32. DIN 1319. Grundlagen der Messtechnik; Techical Report; DIN: Berlin, Germany, 1996.

33. Hamdan, M.A.; Al-qaq, A.M. The prediction of heat transfer coefficient in circulating fluidized bed combustors. Energy Convers. Manag. 2008, 49, 3274-3277. [CrossRef]

34. Syamlal, M.; O'Brien, T. Computer simulation of bubbles in a fluidized bed. AIChE Symp. Ser. 1989, 85, $22-31$.

35. Wen, C.Y.; Yu, Y.H. Mechanics of fluidization. Chem. Eng. Prog. Symp. Ser. 1966, 162, 100-111.

36. Gidaspow, R.B.D.; Ding, J. Hydrodynamics of circulating fluidized beds: Kinetic theory approach. In Proceedings of the 7th Engineering Foundation Conference on Fluidization, Gold Coast, Australia, 3-8 May 1992; pp. 75-82.

37. Min, J.; Drake, J.B.; Heindel, T.J.; Fox, R.O. Experimental validation of CFD simulations of a lab-scale fluidized-bed reactor with and without side-gas injection. AIChE J. 2010, 56, 1434-1446. [CrossRef]

38. Behjat, S.S.Y.; Hashemabadi, S.H. CFD modeling of hydrodynamic and heat transfer in fluidized bed reactors. Int. Commun. Heat Mass Transf. 2008, 35, 357-368. [CrossRef]

39. Wang, J.; van der Hoef, M.A.; Kuipers, J.A.M. Why the two-fluid model fails to predict the bed expansion characteristics of Geldart A particles in gas-fluidized beds: A tentative answer. Chem. Eng. Sci. 2009, 64, 622-625. [CrossRef]

40. Lun, C.K.K.; Savage, S.B.; Jeffrey, D.J.; Chepurniy, N. Kinetic theories for granular flow: Inelastic particles in Couette flow and slightly inelastic particles in a general flowfield. J. Fluid Mech. 1984, 140, 223-256. [CrossRef]

41. Schaeffer, D.G. Instability in the evolution equations describing incompressible granular flow. J. Differ. Equ. 1987, 66, 19-50. [CrossRef]

42. Gunn, D.J. Transfer of heat or mass to particles in fixed and fluidised beds. Int. J. Heat Mass Transf. 1978, 21, 467-476. [CrossRef]

43. Kuipers, J.A.M.; Prins, W.; van Swaaij, W.P.M. Numerical calculation of wall-to-bed heat-transfer coefficients in gas-fluidized beds. AIChE J. 1992, 38, 1079-1091. [CrossRef]

44. Schmidt, A.; Renz, U. Numerical prediction of heat transfer between a bubbling fluidized bed and an immersed tube bundle. Heat Mass Transf. 2005, 41, 257-270. [CrossRef]

45. ANSYS Inc. ANSYS Fluent 16.2 Users Guide. Available online: http://www.pmt.usp.br/academic/ martoran/notasmodelosgrad/ANSYS\%20Fluent\%20Users\%20Guide.pdf (accessed on 10 July 2019).

46. Yusuf, R.; Melaaen, M.C.; Mathiesen, V. CFD modeling of heat transfer in gas fluidized bed. In Proceedings of the Fourth International Conference on CFD in the Oil and Gas, Metallurgical \& Process Industries SINTEF/NTNU, Trondheim, Norway, 6-8 June 2005.

47. Armstrong, L.M.; Gu, S.; Luo, K.H. Study of wall-to-bed heat transfer in a bubbling fluidised bed using the kinetic theory of granular flow. Int. J. Heat Mass Transf. 2010, 53, 4949-4959. [CrossRef]

48. Lan, X.; Xu, C.; Gao, J.; Al-Dahhan, M. Influence of solid-phase wall boundary condition on CFD simulation of spouted beds. Chem. Eng. Sci. 2012, 69, 419-430. [CrossRef]

49. Zhao, Y.; Ding, T.; Zhu, L.; Zhong, Y. A specularity coefficient model and its application to dense particulate flow simulations. Ind. Eng. Chem. Res. 2016, 55, 1439-1448. [CrossRef]

50. Schreiber, M.; Asegehegn, T.W.; Krautz, H.J. Numerical and experimental investigation of bubbling gas-solid fluidized beds with dense immersed tube bundles. Ind. Eng. Chem. Res. 2011, 50, 7653-7666. [CrossRef]

51. Guo, Y.; Deng, B.; Ge, D.; Shen, X. CFD simulation on hydrodynamics in fluidized beds: Assessment of gradient approximations and turbulence models. Heat Mass Transf. 2015, 51, 1067-1074. [CrossRef]

52. Shah, M.T.; Utikar, R.P.; Pareek, V.K.; Tade, M.O.; Evans, G.M. Effect of closure models on Eulerian-Eulerian gas-solid flow predictions in riser. Powder Technol. 2015, 269, 247-258. [CrossRef] 
53. Cooper, S.; Coronella, C.J. CFD simulations of particle mixing in a binary fluidized bed. Powder Technol. 2005, 151, 27-36. [CrossRef]

54. Paschedag, A.R. CFD in der Verfahrenstechnik, Einleitung, Allgemeine Grundlagen und mehrphasige Anwendungen; Wiley-VCH Verlag GmbH \& Co. KGaA: Weinheim, Germany, 2005.

55. Celmins, A. Representation of two-phase flows by volume averaging. Int. J. Multiph. Flow 1988, 14, 81-90. [CrossRef]

56. Loha, C.; Chattopadhyay, H.; Chatterjee, P.K. Assessment of drag models in simulating bubbling fluidized bed hydrodynamics. Chem. Eng. Sci. 2012, 75, 400-407. [CrossRef]

2019 by the authors. Licensee MDPI, Basel, Switzerland. This article is an open access article distributed under the terms and conditions of the Creative Commons Attribution (CC BY) license (http:/ / creativecommons.org/licenses/by/4.0/). 